\title{
INOVAÇÃO NO PROCESSO DA PRODUÇÃO DE DUBLAGEM E LEGENDAGEM PARA REDUÇÃO DE RETRABALHOS E PERDAS OPERACIONAIS E FINANCEIRAS
}

Dennis Marques Reis

Mestre em Administração do Desenvolvimento de Negócios.

Gerente de transformação e sistemas internos da Sinqia. E-mail:dennismreis@gmail.com

\section{Marcos Antonio Franklin}

Doutor em Administração de Empresas pela Universidade Presbiteriana Mackenzie e Mestre em Qualidade pela Universidade Estadual de Campinas (Unicamp). Professor do mestrado profissional em Administração do Desenvolvimento de Negócios da Universidade Presbiteriana Mackenzie (UPM).

E-mail:franklin.marcos@gmail.com 


\section{RESUMO}

Com o uso da abordagem de Marcondes et al. (2017), este relato tecnológico teve a finalidade de apresentar soluções para o problema de eficiência no processo de produção da empresa Centauro Comunicaciones, do setor de dublagem e legendagem. A sua matriz está sediada em Bogotá, na Colômbia, e a operação, no Brasil, na capital de São Paulo. Para entender o problema, foi realizado um diagnóstico utilizando as técnicas de entrevista, brainstorm, Swot e pesquisa qualitativa. O objetivo deste trabalho foi buscar a redução de retrabalhos e perdas operacionais e financeiras do processo de produção de dublagem e legendagem. Após a realização do diagnóstico, identificaram-se problemas em processos, tecnologia e pessoas. Assim, elaboraram-se propostas de soluções com seus respectivos planos de ações: a aplicação da inovação tecnológica, considerando o redesenho de processo, a automatização das atividades e o programa de avaliação de desempenho dos profissionais. A complexidade na elaboração do trabalho foi elevada, pois requereu que a empresa adotasse a política de meritocracia, levando os funcionários para uma nova cultura de remuneração, com base no resultado com produtividade diferenciada, atrelado ao ganho maior. Com isso, os impactos obtidos foram: 1. Redução do prazo de entrega dos projetos dos clientes, da média de 35 dias para 25; 2. Queda no índice de retrabalhos em 2018, sendo, no mês de maio, em torno de $44 \%$; agosto, $20 \%$; setembro, $14 \%$; chegando, em outubro, a $4 \%$; e 3 . Resultados financeiros, quais sejam, a perda com retrabalho no valor de $\mathrm{R} \$ 55.860,00$ no mês de maio de 2018 , em agosto do mesmo ano foi reduzida para $\mathrm{R} \$ 29.820,00$ e, em outubro, para $\mathrm{R} \$ 1.260,00$.

\section{PALAVRAS-CHAVE}

Retrabalhos. Inovação tecnológica. Processos. Avaliação de desempenho. 


\section{INTRODUÇÃO}

As empresas, nos dias atuais, buscam mais eficiência em seus processos e a entrega de produtos e serviços com maior valor agregado aos seus clientes. Assim como em outros setores, a dublagem e a legendagem têm passado por mudanças no segmento, desde a entrada de novos concorrentes, gerando expectativas em relação aos produtos entregues com prazos mais justos para a conclusão dos projetos. Utilizando a metodologia para trabalhos práticos e aplicados, de acordo com Marcondes et al. (2017), este trabalho tem como objetivo propor soluções para a empresa, a fim de melhorar o processo de produção de dublagem e legendagem. Na busca de solucionar o problema de redução de retrabalhos e perdas operacionais e financeiras no processo de dublagem e legendagem, foram estudadas e aplicadas técnicas e ferramentas que puderam trazer os resultados esperados pela empresa. Dessa forma, ao fim deste trabalho, apresentou-se um redesenho do processo atual, considerando as necessidades permeadas por correção, o que ocorreu ao longo de sua execução, bem como validação de soluções propostas para sua melhoria. Desse modo, foi possível manter a empresa competitiva em seu segmento de atuação.

\section{CONTEXTO E A REALIDADE INVESTIGADA}

\section{A empresa}

A empresa Centauro Comunicaciones foi o estúdio pioneiro em dublagem e legendagem para a indústria cinematográfica, a televisão mundial, as plataformas de videogames e outros meios audiovisuais. Criada na Colômbia há mais de 35 anos, é uma pequena empresa familiar que se especializou na dublagem para o espanhol, o português brasileiro e o inglês norte-americano. A partir de uma produtora cinematográfica, com instalações de dublagem em Bogotá, na Colômbia, aproveitou-se dos estúdios de gravação nos quais produzia seus filmes para dar os primeiros passos nesse mercado (CENTAURO, 2018). A matriz da empresa fica na cidade de Bogotá, na Colômbia, e a operação está sediada no Brasil, na capital de São Paulo, sendo este último o local onde foi realizado este relato tecnológico. Atualmente, a empresa possui uma estrutura enxuta que se divide em três 
áreas de atuação: administrativa, produção e financeira. A empresa, atualmente, está presente no Brasil, na Colômbia, no México e nos Estados Unidos. Atuando no mercado brasileiro desde 1992, tem como clientes programadoras de conteúdo, tais como: Viacom, VC Medios, AE Networks, Sesame Group, Fox, Flac, NatGeo, Netflix e BBC (CENTAURO, 2018). Em seu segmento, os principais concorrentes no Brasil são os estúdios de dublagem VoxMundi, Dublavídeo, Grupo Massias, que operam na cidade de São Paulo, e Telefilm, AUDIO NEWS e Delarte, sediados no Rio de Janeiro (CENTAURO, 2018).

\section{O negócio}

O mercado de dublagem e legendagem no Brasil tem tido um relativo crescimento, e, segundo Maria (2017), os serviços de filmes e séries de televisão via streaming, como Netflix e Amazon, investiram muito na dublagem. Esse crescimento também já havia sido relatado por Barbosa e Lírio (2015), os quais citaram que, dos 157,2 milhões de ingressos de cinema vendidos em 2014, no Brasil, 59\% foram destinados a filmes dublados - quase o dobro do total de público que assistiu a filmes legendados (28\%). Barbosa e Lírio (2015) argumentam que o crescimento do conteúdo dublado, como dominante na TV por assinatura, é impulsionado pelo aumento do setor - em grande parte devido ao crescimento das classes C e D. Para o Instituto Brasileiro de Defesa do Consumidor Idec (2013), esse crescimento ocorreu porque, segundo estudo realizado, um em cada cinco brasileiros assiste à TV por assinatura.

Em um breve histórico sobre a dublagem de filmes elaborado por Barbosa e Lírio (2015), verifica-se que somente a partir de 1938 chegou a versão dublada ao país, com o filme Branca de Neve e os sete anões nos cinemas. Na TV, a situação era outra. Nas décadas de 1950 e 1960, a dublagem ainda não era utilizada no país. Além disso, a qualidade da exibição de programas legendados era tão baixa que dificultava a leitura das legendas. A solução apresentada foi dublar os filmes e seriados transmitidos na TV, o que resultou no surgimento de inúmeros estúdios de dublagem pelo país, principalmente no eixo Rio-São Paulo.

$\mathrm{Na}$ sequência deste estudo, expõe-se um maior detalhamento sobre o mercado de atuação e suas especificidades, em que a Centauro está inserida. 


\section{mercado}

A atuação da empresa Centauro ocorreu num cenário de aproveitamento de um mercado que mostrou um crescimento devido à geração de conteúdo realizado pelas produtoras de cinema e operadoras de streaming e TV por assinatura. Como foi detalhado anteriormente, o brasileiro tem a preferência pela programação dublada em detrimento do áudio original (CENTAURO, 2018). Citou-se, previamente, que as principais casas de dublagem se encontram no eixo Rio-São Paulo (CENTAURO, 2018). Nessas praças, segundo Braga (2015), o quadro de dubladores, entre as duas cidades, girava em torno de 600 profissionais. Já Maria (2017) explanou que, na capital fluminense, o Sindicato dos Artistas e Técnicos em Espetáculos de Diversões (Sated-RJ) dá conta da existência de, pelo menos, 20 estúdios de dublagem e de 500 atores atuantes. Afirmou ainda que, em São Paulo, os números são semelhantes.

Esses profissionais são muito requisitados, e a renovação de quadro depende de um processo muito longo a ser percorrido, já que, para se tornar um dublador, é necessário que o interessado seja um ator, com registro profissional na Delegacia Regional do Trabalho. Mesmo quem já trabalha com locução há anos necessita desse documento. Portanto, é necessário ser ator, com especialização em dublagem (CENTAURO, 2018). Por causa do momento de crescimento de demanda e da escassez na formação de novos talentos em São Paulo e Rio de Janeiro, outros locais têm aparecido como concorrência ao mercado: alguns estúdios estão se estabelecendo em Belo Horizonte e Campinas.

Segundo informações fornecidas pelo time de gestão da Centauro, a profissão de dublador é regulamentada e os valores de hora trabalhada por dublador significam os principais custos variáveis da empresa, representando, atualmente, algo em torno de $60 \%$. Esse cenário é idêntico nos demais estúdios de gravação, independentemente da praça de atuação (CENTAURO, 2018). Outro aspecto a ser considerado no caso específico da Centauro é o fato de que as suas principais receitas são negociadas em contratos com grandes produtoras e distribuidoras de conteúdo, conforme citado na seção "A empresa". Esse ponto faz com que a efetividade na produção do processo de dublagens tenha que ser assertiva, pois os custos envolvidos e a qualidade esperada pelos clientes são altos (CENTAURO, 2018). 
Para Toledo et al. (2012), qualidade é uma das palavras mais difundidas da sociedade. Nas empresas, ela pode se comparar com outras palavras como: produtividade, competitividade, integração e ética. Entretanto, a palavra qualidade possui um subjetivismo associado e um uso bem genérico em seu emprego, representando temas distintos, podendo ser identificada e observada pelas características de objetos ou pessoas. Ainda segundo os autores, qualidade é o resultado de interpretação de uma ou mais situações analisadas das pessoas ou dos objetos. Em suma, as características, as intensidades e a forma de mensuração da qualidade podem ou não ser subjetivas. Para a Centauro, a qualidade de seus serviços, processos e entregas estão associadas ao cumprimento dos prazos e ao atendimento das expectativas técnicas e artísticas de seus clientes.

\section{ENTENDIMENTO DO PROBLEMA}

\section{Passos do processo}

A empresa Centauro, ciente da evolução por que seu negócio precisa passar para manter-se competitiva em um cenário em que a tecnologia tem tomado destaque e os custos impactam diretamente o seu resultado operacional, colocou-se à disposição para que um projeto fosse conduzido, de modo a clarificar quais são os principais problemas que a empresa enfrenta atualmente. Dessa forma, com base na metodologia para trabalhos práticos e aplicados (MARCONDES et al., 2017), para o entendimento do problema, realizou-se uma reunião, no final do mês de março de 2018, com o fundador da empresa, Gustavo Nieto, o diretor administrativo da operação Brasil e o gerente de produção. Nessa reunião, apresentaram-se todo o contexto do projeto e as prováveis metodologias que poderiam ser aplicadas para o levantamento dos problemas. Também se definiu que seriam aplicadas duas metodologias para o levantamento do problema a ser trabalhado, ou seja, para a execução dessa etapa de entendimento, houve uma sessão de brainstorm e a aplicação de um roteiro estruturado de perguntas, que serão mais bem explorados na sequência.

Primeiramente, foi realizada uma dinâmica de brainstorm. Segundo Schiavon (2017), o brainstorm é uma técnica na qual se busca gerar uma infinidade de ideias na procura pela solução de algum problema. A técnica foi criada com o objetivo de aprimoramento de pro- 
jetos. Ainda, conforme Schiavon (2017), o mais importante da aplicação da técnica é que os participantes saibam quais são os objetivos a se atingir para a busca de ideias. O Quadro 1 representa a consolidação do resultado obtido nessa coleta de ideias, que foi conduzida por meio de um brainstorm estruturado, em que os gestores puderam compartilhar seus insights.

QUADRO 1 - Reunião inicial com a diretoria da Centauro - sessão de brainstorm

\section{Sessão de brainstorm - Centauro}

Possibilidade de utilização do sistema legado da Centauro em empresas concorrentes - venda de serviços.

Utilização de ferramenta de inteligência artificial para o processo de tradução de textos.

Maior automatização do processo de produção de dublagem e legendagem.

Redução dos retrabalhos do processo de produção de dublagem e legendagem.

Aplicação de métricas de desempenho para avaliação dos processos.

Implementação de programa de meritocracia atrelado ao desempenho individual.

Migração dos estúdios da praça de São Paulo para outra cidade.

Migração dos estúdios de São Paulo para Miami.

Formação de escola de dubladores/diretores para aproveitamento de mão de obra qualificada.

Utilização de estúdio de produção de conteúdo das agências de publicidade.

Venda de serviços de locução para agências produtoras de conteúdo.

Fonte: Elaborado pelos autores.

Para dar continuidade ao entendimento do problema a ser solucionado e verificar a maneira como seriam coletadas as informações, discutiu-se com a diretoria da empresa acerca de um método para o desenho e a realização do projeto. Como etapa posterior ao brainstorm, ficou definida a aplicação de um roteiro estruturado com perguntas à diretoria. Segundo Manzini (1990), o roteiro de entrevistas tem como principal função auxiliar o entrevistador no momento de encontrar informações sobre o objetivo da pesquisa e de sua execução, de modo que ele possa organizar-se e facilitar a transmissão das informações de forma simples e precisa. No roteiro estruturado aplicado à diretoria da Centauro, adotaram-se perguntas abertas para o entendimento do problema. O Quadro 2 apresenta os assuntos abordados pelo roteiro e a opinião dos executivos da empresa. 
QUADRO 2 - Roteiro aplicado à diretoria da Centauro

\begin{tabular}{|c|c|c|c|}
\hline Objetivo & Pergunta & Resposta - Executivo A & Resposta - Executivo B \\
\hline \multirow{4}{*}{$\begin{array}{l}\text { Entender } \\
\text { quais seriam } \\
\text { os principais } \\
\text { problemas a } \\
\text { serem } \\
\text { tratados na } \\
\text { organização }\end{array}$} & $\begin{array}{l}\text { Que desempenho } \\
\text { é considerado } \\
\text { insatisfatório? Que } \\
\text { sistemas, processos } \\
\text { e recursos } \\
\text { provocam o baixo } \\
\text { desempenho? }\end{array}$ & $\begin{array}{l}\text { O que não atende plenamente o } \\
\text { cliente no que diz respeito à } \\
\text { qualidade e ao prazo, ou atende } \\
\text { parcialmente, mas não da maneira } \\
\text { correta, não seguindo as diretrizes } \\
\text { de atendimento individual. }\end{array}$ & $\begin{array}{l}\text { Ultimamente, temos tido } \\
\text { problemas no processo final da } \\
\text { entrega, ou seja, o produto } \\
\text { chega ao cliente sem todas as } \\
\text { especificações técnicas ou uma } \\
\text { especificação linguística, } \\
\text { gerando, assim, várias rejeições. }\end{array}$ \\
\hline & $\begin{array}{l}\text { Qual é a relevância } \\
\text { dessas dificuldades } \\
\text { e deficiências para } \\
\text { o alcance de } \\
\text { objetivos dos } \\
\text { negócios? }\end{array}$ & $\begin{array}{l}\text { O negócio está muito focado no } \\
\text { fator humano. Há uma baixa } \\
\text { escolaridade, em geral, para o } \\
\text { manejo das tarefas do dia a dia da } \\
\text { empresa, além de um descaso para } \\
\text { com a maneira correta de seguir as } \\
\text { diretrizes de atendimento (seja este } \\
\text { direto ou no quesito expectativas } \\
\text { na entrega do produto). }\end{array}$ & $\begin{array}{l}\text { São extremamente relevantes, } \\
\text { pois implicam diretamente em } \\
\text { um desgaste de nossa imagem, } \\
\text { assim como na possível perda } \\
\text { de alguns trabalhos ou da } \\
\text { conta. }\end{array}$ \\
\hline & $\begin{array}{l}\text { Quais seriam as } \\
\text { possíveis causas } \\
\text { dessas } \\
\text { deficiências? }\end{array}$ & $\begin{array}{l}\text { Baixa qualificação do pessoal } \\
\text { aliada à falta de orientação e } \\
\text { monitoramento constante por } \\
\text { parte da gestão da empresa. }\end{array}$ & $\begin{array}{l}\text { Falta de informação, desvio de } \\
\text { informação, troca de dados } \\
\text { sobre o andamento da } \\
\text { produção, preparação da } \\
\text { produção, controle final do } \\
\text { produto enviado. }\end{array}$ \\
\hline & $\begin{array}{l}\text { O que a empresa } \\
\text { quer que aconteça } \\
\text { como resultado do } \\
\text { projeto? }\end{array}$ & $\begin{array}{l}\text { Seja economicamente viável, com } \\
\text { um processo melhor e mais } \\
\text { focado na qualidade e controle de } \\
\text { prazos. }\end{array}$ & $\begin{array}{l}\text { Melhoria de processos, abrir } \\
\text { novos mercados e vislumbrar } \\
\text { novos nichos ou negócios. }\end{array}$ \\
\hline
\end{tabular}

Fonte: Elaborado pelos autores.

Por meio do Quadro 2, percebeu-se a necessidade de detalhar um processo que é fundamental para a operação da Centauro, o de produção de dublagem e legendagem. Esse é o principal processo da empresa e o responsável pelas receitas financeiras, além de ser o principal produto entregue aos clientes, oriundo dos projetos realizados. Pôde-se verificar que, atualmente, a Centauro convive com um problema relativo à conformidade de entrega de seus produtos e serviços de dublagem e legendagem aos clientes, em deter- 
minadas etapas do processo de produção. Esses problemas se encontram nos gates de aprovação do processo. Os retrabalhos têm causado perda operacional e financeira.

Nesse sentido, é oportuno esclarecer o que se entende como retrabalho. Segundo Coelho et al. (2017), pode existir uma série de "re" nas organizações. Um "re" representa a repetição da mesma atividade de forma intermitente. O retrabalho é o mais comum dentre eles e representa a correção de um erro. Por conta disso, deve ser eliminado, pois pode acarretar perdas financeiras, de qualidade e de produtividade pelo simples fato de ter que repetir - mais de uma vez - aquilo que poderia ter sido realizado em apenas uma. Quando se trata de retrabalhos em seu processo produtivo, devem-se considerar também os desperdícios e os custos deles para a organização.

Esse problema de conformidade foi citado em vários momentos pelos responsáveis pela empresa que já vêm, ao longo de dois anos, apurando o aumento de intensidade de reclamações. Existe também um aumento de trabalho provocado pela entrada de novos clientes e por especificações técnicas e de qualidade mais exigentes. As métricas de apuração das perdas operacionais e financeiras não são gerenciadas de forma assertiva, ficando na percepção de valores macro. A empresa já está implementando o controle de retrabalhos por projeto, o que já permite identificar o aumento das ocorrências. O Gráfico 1 reflete uma situação específica apurada em um projeto do cliente VC Medios.

GRÁFICO 1 - Apuração de retrabalhos em um projeto do cliente VC Medios

TOTAIS RETAKES

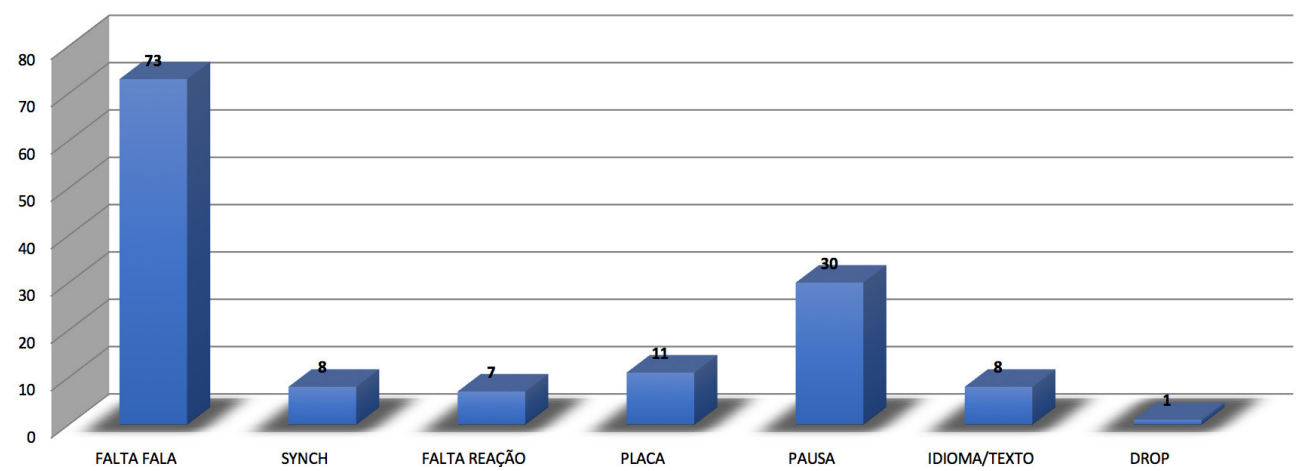

Fonte: Centauro (2018). 
Dessa forma, o objetivo do projeto foi reduzir retrabalhos e perdas operacionais e financeiras do processo de produção de dublagem e legendagem. Esse será o direcionador para que se possa buscar um resultado efetivo com a execução do projeto. Para tanto, na sequência, explana-se o detalhe de como foi dado apoio ao processo na Centauro.

\section{DIAGNÓSTICO DO PROBLEMA}

\section{Problema}

Na definição do problema a ser trabalhado, o processo de produção de dublagem e legendagem passou por identificação, validação e desenho, mediante a aprovação da diretoria, com a intenção de clarificar o momento em que aconteciam as não conformidades, bem como os erros que permitiam a manutenção das etapas sem a devida assertividade. Analisaram-se e monitoraram-se as etapas do processo, bem como foram identificadas as causas que ocasionavam as perdas operacionais e financeiras.

\section{Mapeamento da situação, métodos e técnicas utilizadas}

Para a realização do diagnóstico do problema, empregaram-se técnicas que deram suporte ao desenvolvimento deste trabalho. Os passos adotados foram a aplicação da matriz Swot, o mapeamento de processos e as entrevistas com stakeholders.

\section{Aplicação da ferramenta Swot}

A matriz Swot - acrônimo de strengths (forças), weaknesses (fraquezas), opportunities (oportunidades) e threats (ameaças) - é uma ferramenta desenvolvida e aplicada em diversas empresas. Segundo Caetano e Sampaio (2016), esse modelo é adotado pelas organizações com o propósito de torná-las capazes de compreender o ambiente interno quanto às suas forças e às suas fraquezas, bem como o ambiente externo, no que tange às suas oportunidades e às suas ameaças. Essa ferramenta oferece ao gestor uma visão sistêmica 
da realidade de sua organização, facilitando a tomada de decisão. Os autores citaram que a matriz Swot não possibilita apenas conhecer o cenário vigente da organização, mas também prospectar por meio de planejamentos estratégicos. A matriz Swot da Centauro foi consolidada em uma reunião ocorrida em maio de 2018 com os gestores da empresa. A consolidação passou a representar a visão unificada da gestão. A Figura 1 apresenta o resultado obtido por meio da consolidação realizada, considerando a somatória das visões dos executivos da empresa.

\begin{tabular}{|c|c|c|}
\hline & Fatores positivos & Fatores negativos \\
\hline $\begin{array}{l}\text { 을 } \\
\text { 를 }\end{array}$ & $\begin{array}{l}\text { Forças } \\
\text { - Nome da empresa no mercado } \\
\text { - Tempo de atuação no mercado } \\
\text { - Serviços multi-idiomas } \\
\text { - } \text { Qualidade locais de atuação - Multissites } \\
\text { - } \text { Fucililínguas } \\
\text { - } \text { aplicaçãa e rapidez na tomada de decisão e sua } \\
\text { Adaptação as necessidades dos clientes / mercados }\end{array}$ & 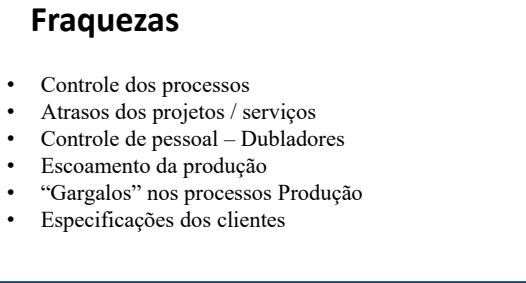 \\
\hline 응 & $\begin{array}{l}\text { Oportunidades } \\
\text { - Mudança de cidade para diminuição de custos } \\
\text { - Desenvolver um ERP para automatizar processos } \\
\text { incluindo tradução e sonorização } \\
\text { - Mercado outside Brasil } \\
\text { - Novos Serviços - regionalização e legendas } \\
\text { - Desenvolvimento de software, aplicativos de } \\
\text { dublagem e tradução } \\
\text { Escola de dublagem }\end{array}$ & $\begin{array}{ll} & \text { Ameaças } \\
\text { - } & \text { Novos entrantes } \\
\text { - } & \text { Praças diferentes - regional outside Brasil } \\
\text { - } & \text { Novas tecnologias } \\
\text { - } & \text { Coneaças - sindicais e de convenção trabalhistas } \\
\text { - } & \text { Mercado sujeito a mudanças rápidas quanto a preço, } \\
& \text { aumento do custo de mão de obra dos atores em SP }\end{array}$ \\
\hline
\end{tabular}

FIgURA 1 - Matriz Swot - Centauro consolidada

Fonte: Elaborada pelos autores.

Dessa forma, a continuação do diagnóstico se deu com o mapeamento de processo que é a próxima seção a ser abordada.

\section{Mapeamento do processo}

Nessa etapa do diagnóstico, foi definida a necessidade de desenhar o processo de produção de dublagem e legendagem para entender todo o funcionamento desse encadea- 
mento de negócio. Em sua definição de processos, Andreoli e Rossini (2015) argumentaram que o processamento é a transformação responsável pela conversão de elementos de entrada em elementos de saída. Outro ponto observado é o de que uma empresa tem vários processos diferentes e com objetivos, métricas e métodos distintos, sendo necessário identificá-los para que seu gerenciamento consiga alcançar os resultados esperados. Para a Association of Business Process Management Professionals - ABPMP (2013), o processo de negócio é um trabalho que entrega valor ao cliente ou apoia a gerência e outros processos. Esse trabalho pode ser "ponta a ponta”, interfuncional e até mesmo interorganizacional. A noção do trabalho "ponta a ponta" e "interfuncional" é chave, pois envolve todo o trabalho, cruzando os limites funcionais para entregar valor aos clientes.

Ainda, segundo a Association of Business Process Management Professionals (2013), a modelagem de processos é o conjunto de atividades que são criadas para se representar um processo de negócio existente ou proposto. Para tanto, é utilizada a ferramenta fluxograma, que, de acordo com Araújo (2001), possibilita mostrar, por meio de símbolos, a sequência de atividades simples ou complexas, caracterizando as operações e permitindo realizar análises nos processos. Para Oliveira (1997), o fluxograma representa, com racionalidade, a síntese de rotinas e procedimentos envolvidos, processados e emitidos pelas áreas organizacionais.

Essa notação foi adotada para o mapeamento do processo de produção de dublagem e de legendagem da Centauro. As figuras 2 e 3 apresentam, de forma sequenciada, o processo executado atualmente na empresa. Esse mapeamento de processos foi conduzido por intermédio de uma sessão de entrevista com o gerente de operações da empresa e aborda a sequência do processo atual, em que foi possível notar a complexidade existente e a quantidade de atividades envolvidas em cada uma das áreas participantes.

Participam do processo as áreas de vendas e financeira, subordinadas à diretoria administrativa; as áreas subordinadas à gerência de produção, como tráfego, idiomas, produção, pós-produção, controle de qualidade (quality control - QC), além dos clientes. 


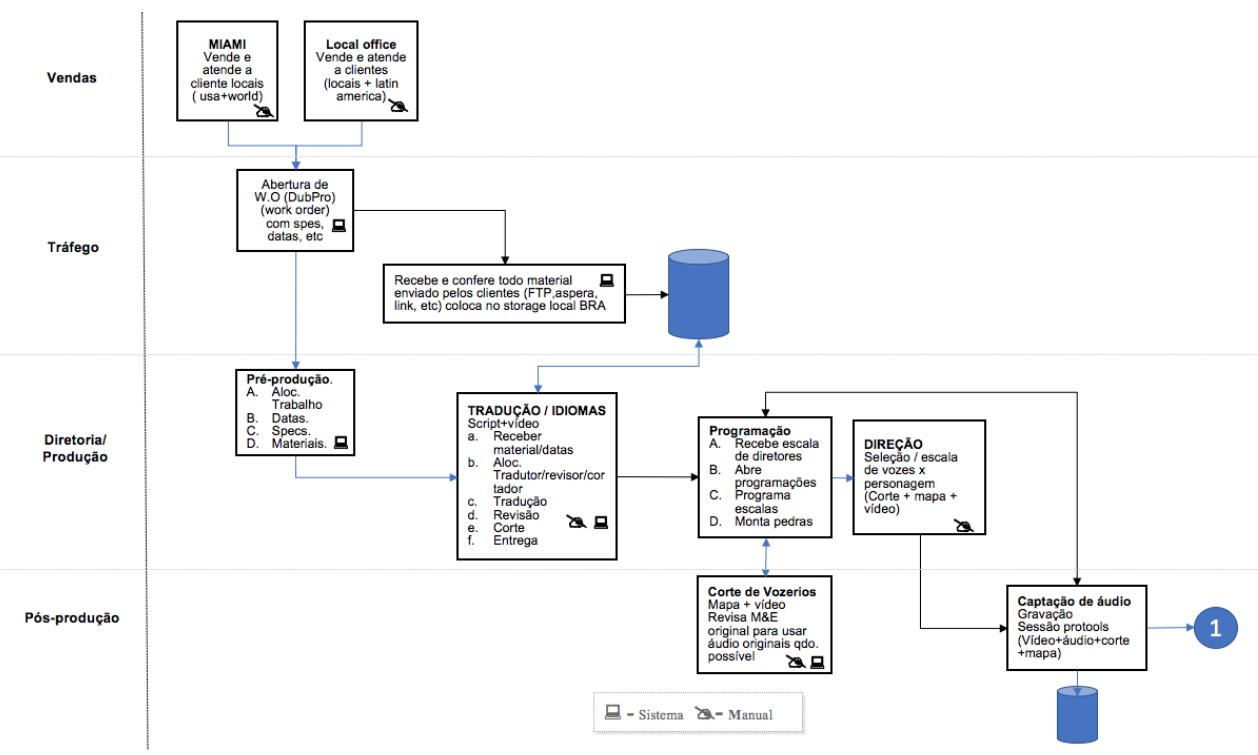

FIGURA 2 - Processo atual de produção de dublagem e legendagem - parte 1

Fonte: Elaborada pelos autores.

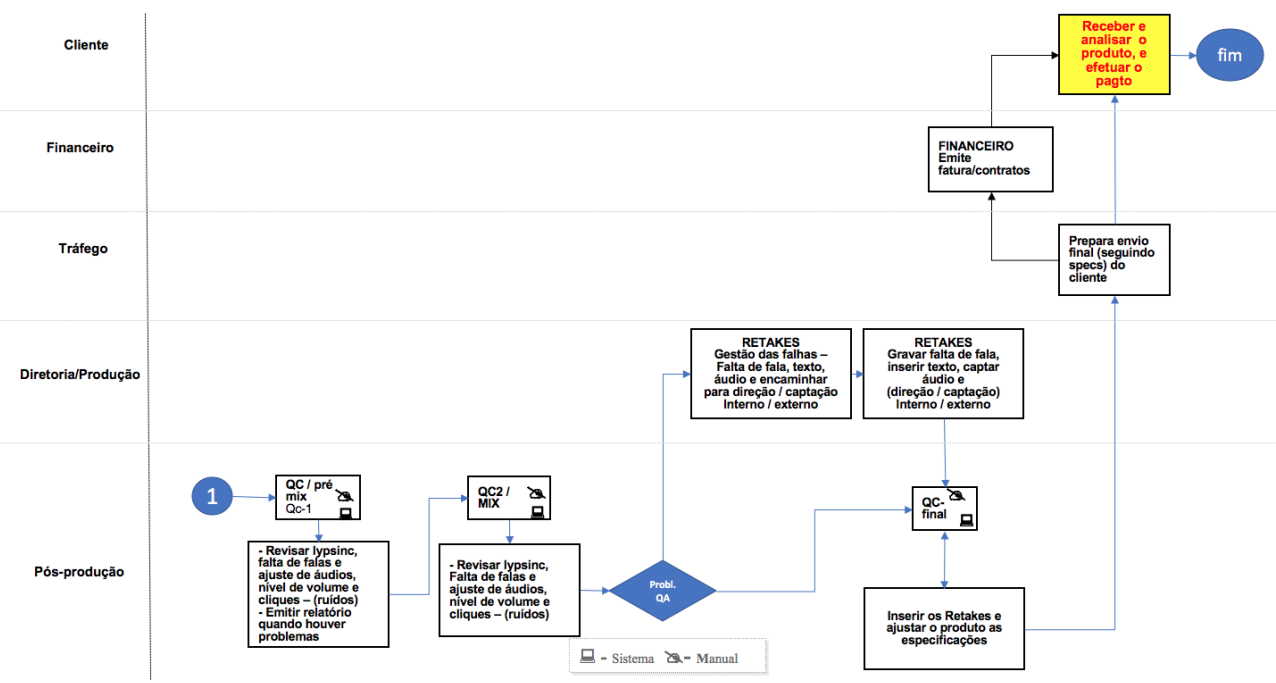

FIGURA 3 - Processo atual de produção de dublagem e legendagem - parte 2

Fonte: Elaborada pelos autores. 
O tempo averiguado de execução dos projetos gira em torno de 35 dias, desde o início da produção até a entrega ao cliente. A Figura 4 representa graficamente o tempo médio de produção e o paralelismo de atividades executadas pelas áreas.

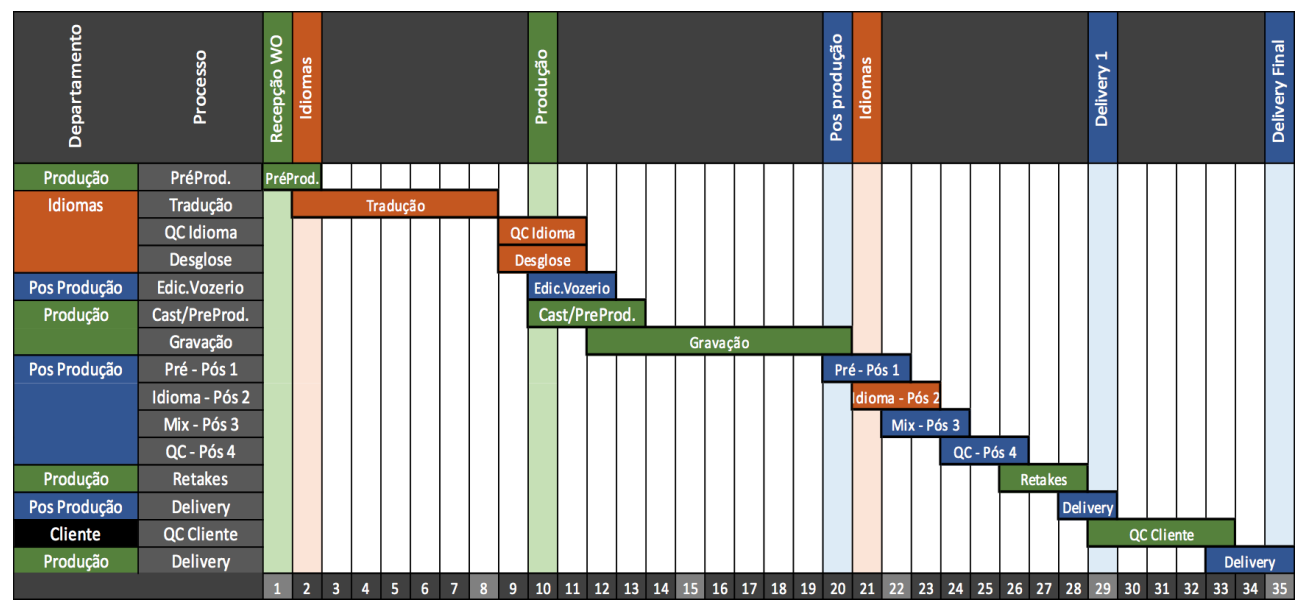

FIgURA 4 - Tempo médio de produção

Fonte: Centauro (2018).

Como passo final do diagnóstico, foi utilizado o método qualitativo que, segundo Merriam (1998), envolve variadas técnicas e procedimentos de interpretação que procuram essencialmente descrever, decodificar e traduzir o sentido e não a frequência de eventos ou fenômenos do mundo social. Para a coleta de dados, adotou-se a técnica de entrevistas com os envolvidos nas atividades do processo, as quais estão mais bem detalhadas no próximo tópico.

\section{Realização de entrevistas com os principais stakeholders do processo}

Nessa etapa do diagnóstico, foram realizadas entrevistas com os principais stakeholders do processo para o levantamento de problemas e potencialidades de solução. De acordo com Flick (2009), as entrevistas têm como principal característica perguntas "mais ou menos abertas" à situação que se deseja entender, como forma de um guia. Há a 
expectativa de que essas perguntas sejam livremente respondidas pelo entrevistado. Para certificar-se dos conteúdos, antes da realização das entrevistas, pode-se utilizar uma lista de pontos-chave para a verificação de como foram construídas e formuladas as perguntas.

Para Andreoli e Rossini (2015), apesar de uma entrevista ser estruturada, planejada e, muitas vezes, fechada, ela permite ao gestor sair do roteiro caso alguma informação relevante e não esperada surja e necessite de aprofundamento na mesma hora, de uma interação ou ainda de um feedback. A entrevista em profundidade, conforme Oliveira, Martins e Vasconcelos (2010), é adequada para esse trabalho por causa do destaque às percepções detalhadas, segundo pontos de vista individuais, direcionado a um roteiro semiestruturado. Isso abre a possibilidade de o respondente discorrer sobre a pergunta proposta e permite ao entrevistador guiar uma discussão para o assunto que lhe interessa por meio de perguntas adicionais para elucidar questões, e, dessa forma, pode ocorrer um diálogo mais informal para a obtenção dos objetivos formulados.

Por meio das entrevistas com o time da Centauro, cuja finalidade foi entender em profundidade o conhecimento de cada colaborador no processo de produção de dublagem e legendagem e os principais problemas que enfrentavam em suas atividades dentro do processo, buscou-se identificar a função que o colaborador exercia dentro da empresa, o tempo que possuía de casa, as experiências anteriores dentro do segmento em que a Centauro atua e a existência do entendimento ponta a ponta do processo em que participa. O Quadro 3 mostra o compilado dos problemas apresentados pelos colaboradores da Centauro nas entrevistas.

QUADRO 3 - Lista de problemas - entrevistas com os colaboradores da Centauro

\section{Problemas}

Existe grande pressão por tempo para executar o trabalho.

Apresenta cronograma apertado para a realização dos projetos.

Existem critérios distintos de avaliação entre os controles de qualidade - QC1, QC2 e QC final. 
QUADRO 3 - Lista de problemas - entrevistas com os colaboradores da Centauro

\begin{tabular}{l}
\hline \multicolumn{1}{c}{ Problemas } \\
\hline $\begin{array}{l}\text { Surgem problemas na etapa de produção, que é feita de forma muito rápida, gera excesso de retrabalho } \\
\text { na pós-produção (captação, diretores, atores). }\end{array}$ \\
\hline $\begin{array}{l}\text { Comentam que diretores montam as escalas de atores sem conhecer o produto - sem assistir aos } \\
\text { programas. }\end{array}$
\end{tabular}

Percebem que o recebimento do material que vem do time de tradução acaba chegando "muito em cima da hora" a fim de executar todas as atividades de produção.

Há dificuldade na gestão de agenda dos diretores e dubladores.

Sabe-se que o QC solicita para que sejam revisados e refeitos muitos assuntos que poderiam ser resolvidos internamente - retrabalhos.

Citam que não existe no sistema Duppro Pró a função para reagendamento ou cancelamento do dublador escalado.

Falta comunicação entre: 1. a produção e pós-produção para solicitar os retrabalhos - base nas especificações dos clientes; 2. a tradução e os diretores; e 3. todas as áreas da empresa.

Existe desânimo na atuação, pois a tradução e a pós-produção são cobradas mais pelo prazo do que pela qualidade do produto.

Informam que o produto é entregue sem sincronia, com problemas técnicos, com barulhos, por exemplo.

Falta de comprometimento técnico dos diretores com o produto entregue.

Anunciam que os prazos de entrega do material pelo cliente são muito curtos, basicamente "em cima da hora" de todo o trabalho, com medo de pirataria, havendo várias versões.

Fonte: Elaborado pelos autores.

Participaram das entrevistas profissionais das áreas de pós-produção, produção, retrabalhos, corte, tradução, tráfego, diretores de arte e QC, que têm tempo médio de casa de três anos. Os profissionais entrevistados já possuem experiência no segmento de dublagem e legendagem, tendo, inclusive, passado por outras empresas do mesmo segmento. Foram entrevistados oito colaboradores, conforme Quadro 4. 
QUADRO 4 - Característica dos entrevistados

\begin{tabular}{cccc}
\hline Entrevistados & Função & Tempo de empresa & Sexo \\
\hline 1 & Controle QA & 6 anos & Masculino \\
\hline 2 & Tráfego & 1,2 ano & Masculino \\
\hline 3 & Pós-produção & 4 anos & Masculino \\
\hline 4 & Produção & 2 anos & Feminino \\
\hline 5 & Retrabalho & 4 meses & Feminino \\
\hline 6 & Corte & 5 anos & Masculino \\
\hline 7 & Tradução & 2 anos & Masculino \\
\hline 8 & Diretor de arte & 5 anos & Feminino \\
\hline
\end{tabular}

Fonte: Elaborado pelos autores.

Após a entrevista, identificaram-se problemas que podem gerar impactos diretos no objetivo de eliminar os retrabalhos e as perdas financeiras e operacionais. Destacam-se, aqui, a falta de comunicação entre as áreas e as divergências nos procedimentos do QC, prazos apertados para a execução dos trabalhos e o atendimento às especificações dos clientes. No próximo tópico, são abordadas as análises das informações coletadas no diagnóstico.

\section{Análise das informações obtidas}

Após a realização da coleta de dados relacionados ao diagnóstico do problema acordado com a Centauro, conforme já citado no tópico "Entendimento do problema”, pôde-se verificar que existem vários fatores que levam a empresa a um excesso de retrabalhos e, por consequência, a perdas operacionais e financeiras. Os projetos possuem alta complexidade de execução e devem atender a especificações diversas dos clientes.

Segundo Lafetá, Barros e Leal (2016), a teoria dos projetos busca a compreensão dos fatores e das dimensões que agregam complexidade aos projetos, no intuito de desenvolver soluções adequadas a cada caso. A complexidade do projeto pode estar ligada, por exemplo, com a organização ou tecnologia envolvida. Compreender a complexidade envolvida 
no projeto é importante para o sucesso de sua gestão. Analisar os projetos, sob a ótica da complexidade, possibilita novos olhares acerca da gestão de projetos em que atua.

Há falta de um controle para identificar de forma efetiva quais são as perdas que acontecem ao longo do processo. As informações são imprecisas e não oferecem exatidão nas etapas em que são gerados os desvios. $\mathrm{O}$ não monitoramento de todas as atividades do processo por intermédio de métricas de desempenho dificulta a análise das perdas. A apuração dos retrabalhos que necessitam ser realizados é feita somente no final do processo, ou seja, na etapa de QC. Nesse ponto do processo, os prazos para conclusão desses projetos já são bastante reduzidos, o que coloca em risco a qualidade dos produtos entregues aos clientes.

Existe também falta de comunicação entre as áreas da empresa. Os profissionais têm profundo conhecimento sobre sua área de atuação e limitam-se a focar seus esforços diretamente na execução de sua atividade. Há um sistema na empresa que já gerencia as atividades executadas dentro do processo, entretanto existem tarefas que ainda são manuais e dificultam, dessa forma, a medição do workflow. O próximo tópico trata das soluções propostas aos problemas encontrados, na fase de diagnóstico, e objetiva solucionar o tema principal deste projeto.

\section{PROPOSTAS DE SOLUÇÃO DO PROBLEMA}

Neste tópico, de acordo com a abordagem de Marcondes et al. (2027), são detalhadas as propostas de solução para o problema identificado na Centauro de redução de retrabalhos e de perdas operacionais e financeiras do processo de produção de dublagem e legendagem. As propostas apresentam foco em três pilares: 1. processos; 2. tecnologia; e 3. pessoas. Dessa forma, são exibidos em detalhes os caminhos para se atingir o objetivo proposto neste estudo. Essa automação levou a empresa a uma inovação tecnológica e de processo.

\section{Redesenho do processo}

O processo de dublagem e legendagem passou por sua última revisão no início de 2016. Existia a necessidade de reavaliar como o processo se comportava atualmente e se ele 
atendia às atuais necessidades de negócio. Outra reflexão teve como foco entender se novos pontos de controle poderiam ser introduzidos para garantir que não houvesse avanços de etapas com problemas e somente fossem percebidos erros no QC. Para tanto, o redesenho de processo foi a metodologia que melhor se adaptou a essa necessidade. Segundo a Association of Business Process Management Professionals (2013), o redesenho é o repensar ponta a ponta sobre o processo que está sendo realizado nesse ínterim. Essas mudanças partem de um processo já existente. Por causa do escopo, impacto e risco de implementação, os gestores devem criar um desenho-alvo e dividi-lo em partes para a execução. Ainda segundo a Association of Business Process Management Professionals (2013), deve existir uma visão clara sobre a transformação, de como serão vistos a operação e o desempenho dela. Para muitas organizações, essa nova visão de negócio "de dentro para fora", com a visão do cliente, pode trazer aumento de produtividade, redução de desperdícios e aumento de flexibilidade.

O redesenho do processo englobou os três pilares dessa reestruturação na organização, pois teve como premissa remodelar os papéis e as responsabilidades, considerando o cenário atual de negócio. Essa adaptação de atividades implicou a reorganização de times, pessoas e procedimentos. Outro ponto a ser considerado no redesenho foi a automatização de atividades do processo via sistema. Essa mudança ocasionada pela automatização solicitou uma atenção especial com as pessoas, para que se entendessem os ganhos em produtividade, assim como a melhor eficiência e o melhor controle do processo.

\section{Automatização de sistema}

Para a realização de automatização de processos, certas premissas básicas precisaram ser adotadas, como a relevância da sistematização dentro do processo. Não bastava fazer a gestão de uma atividade no sistema sem que esta realmente trouxesse valor em sua realização. Ademais, partindo do redesenho do processo, as atividades mais importantes e que garantissem a gestão efetiva dos recursos empregados na execução do processo deveriam ser implantadas. Nesse momento, uma série de modelos de gestão de projetos de tecnologia está sendo utilizada pelas empresas. A proposta para implementação das melhorias na Centauro foi calcada na metodologia ágil de projetos. 
Segundo Vidal (2017), a adoção de um modelo de trabalho baseado no ágil deve primordialmente passar por uma transformação cultural da equipe, como também de seus superiores. Dessa forma, os participantes devem estar engajados na execução das atividades e ter atitude e participação. Na época atual, as empresas têm adotado o conceito de desenvolvimento ágil de softwares, utilizando o conceito de prototipação. Para a efetivação das melhorias necessárias no sistema Duppro da Centauro, a aplicação de um modelo ágil de gestão de projetos fez-se necessária a fim de buscar as readequações no processo e uma maior agilidade de implantação, visando eliminar os retrabalhos e melhorar a qualidade dos serviços prestados aos clientes. A metodologia Scrum foi aplicada no desenvolvimento da solução. O Scrum é uma ferramenta que permite controlar as ações de equipes que trabalham em prol de um objetivo comum. Segundo Sutherland (2014), os resultados que o Scrum pode obter com as equipes melhoram drasticamente a produtividade dos projetos.

\section{Pessoas}

No pilar de pessoas, a proposta foi implementar um programa de avaliação de desempenho dos profissionais envolvidos no processo de produção de dublagem e legendagem. Para comprovar os ganhos obtidos pela medição do desempenho, estabeleceu-se que o acompanhamento fosse realizado em uma das áreas da empresa, como piloto. A área escolhida para a execução do teste foi a de idiomas, responsável por relevante parte do processo.

Segundo Lucena (2004), as empresas vivenciam um ambiente de acelerada mudança, o que as coloca em constante avaliação pública. Essas expectativas do mercado fazem com que as organizações obrigatoriamente realizem revisões em seus modelos organizacionais e implementem ações criativas e inovadoras. Para a autora, o desempenho humano não pode ser isolado da dinâmica de uma organização e do ambiente de mercado aos quais ela pertence.

\section{GANHOS COM A SOLUÇÃO}

Neste tópico, serão detalhados os ganhos que podem ser obtidos com a implementação das propostas citadas. Essas propostas vão ao encontro do objetivo estabelecido no traba- 
lho e têm como atributo o aprimoramento de desempenho e a melhor gestão do processo de produção de dublagem e legendagem.

\section{Redesenho do processo}

Com o redesenho do processo, buscou-se uma remodelagem para atender principalmente à diminuição dos retrabalhos que ocorrem no processo de produção. Foram criadas atividades e automatizadas várias etapas do processo, a fim de permitir um melhor gerenciamento das perdas operacionais e financeiras. O redesenho do processo permitiu uma readequação dos papéis, bem como a atribuição de novas responsabilidades ao time. $\mathrm{O}$ acerto das atividades também visou à redução do tempo para a entrega dos projetos aos clientes, objetivando a criação de valor para o principal interessado nos serviços da empresa Centauro.

Segundo Kotler e Armstrong (2007), a criação de valor consiste em criar um forte elo entre o relacionamento da empresa e o cliente. Criado esse valor, a empresa captura dos clientes as vendas e os lucros em uma relação de longo prazo. As empresas, no atual momento, estão fomentando que os departamentos parem de pensar unicamente em seus objetivos e passem a unir-se em torno de uma única causa: a criação de valor ao cliente. Quando se cria valor superior ao cliente, propicia-se um ambiente de fidelização e de retenção, fazendo com que eles permaneçam fiéis, comprando mais seus produtos e serviços.

\section{Automatização de sistema}

A automatização de etapas do processo buscou garantir que todas as mudanças realizadas pudessem ter o suporte de tecnologia no sistema Duppro, que é de propriedade da Centauro. Todas as implementações visaram aperfeiçoar o sistema já em operação, trazendo maior efetividade e agilidade nas tarefas. Dessa forma, buscou-se também a redução de atividades executadas de forma manual e que não possuíam o controle e a gestão devidos. 


\section{Pessoas}

A implantação de um modelo de medição de desempenho dos profissionais da área de idiomas permitiu que uma nova cultura fosse surgindo dentro da organização. Os indicadores de desempenho trouxeram uma nova visão na gestão da área e também nos reais objetivos a serem atingidos pelos profissionais que trabalham nesse time. Outro ganho percebido foi o aumento de produtividade dos profissionais atrelado a uma política de remuneração variável pelo desempenho. A qualidade das entregas e a rapidez nas traduções demonstraram melhora. Essa mudança também foi suportada pela mudança e automatização do processo que permitiram o melhor monitoramento das atividades.

\section{PLANOS DE AÇÕES}

Neste tópico, serão apresentados os quadros dos planos de ações, segundo o modelo de Marcondes et al. (2017). Esses planos foram implantados pela diretoria da empresa Centauro e refletem as propostas apresentadas, as ações realizadas e como estas foram executadas. Também são detalhados os responsáveis e os envolvidos para a execução de cada uma dessas propostas. As propostas aqui apresentadas foram validadas pela diretoria da Centauro e visavam atender aos três pilares propostos na solução do problema: 1. Reduzir os retrabalhos; 2. Eliminar as perdas operacionais e financeiras; e 3. Implementar programa de meritocracia, no que tange ao papel da responsabilidade das pessoas, atualizando processos e tecnologia.

\section{Redesenhar o processo redefinindo papéis e responsabilidades}

Esse plano de ação diz respeito ao redesenho do processo e definição de novas atividades, papéis e responsabilidades conjuntamente aos times que participam do processo de produção. No Quadro 5, podem-se verificar as principais atividades realizadas ao longo da execução do plano de ação. 


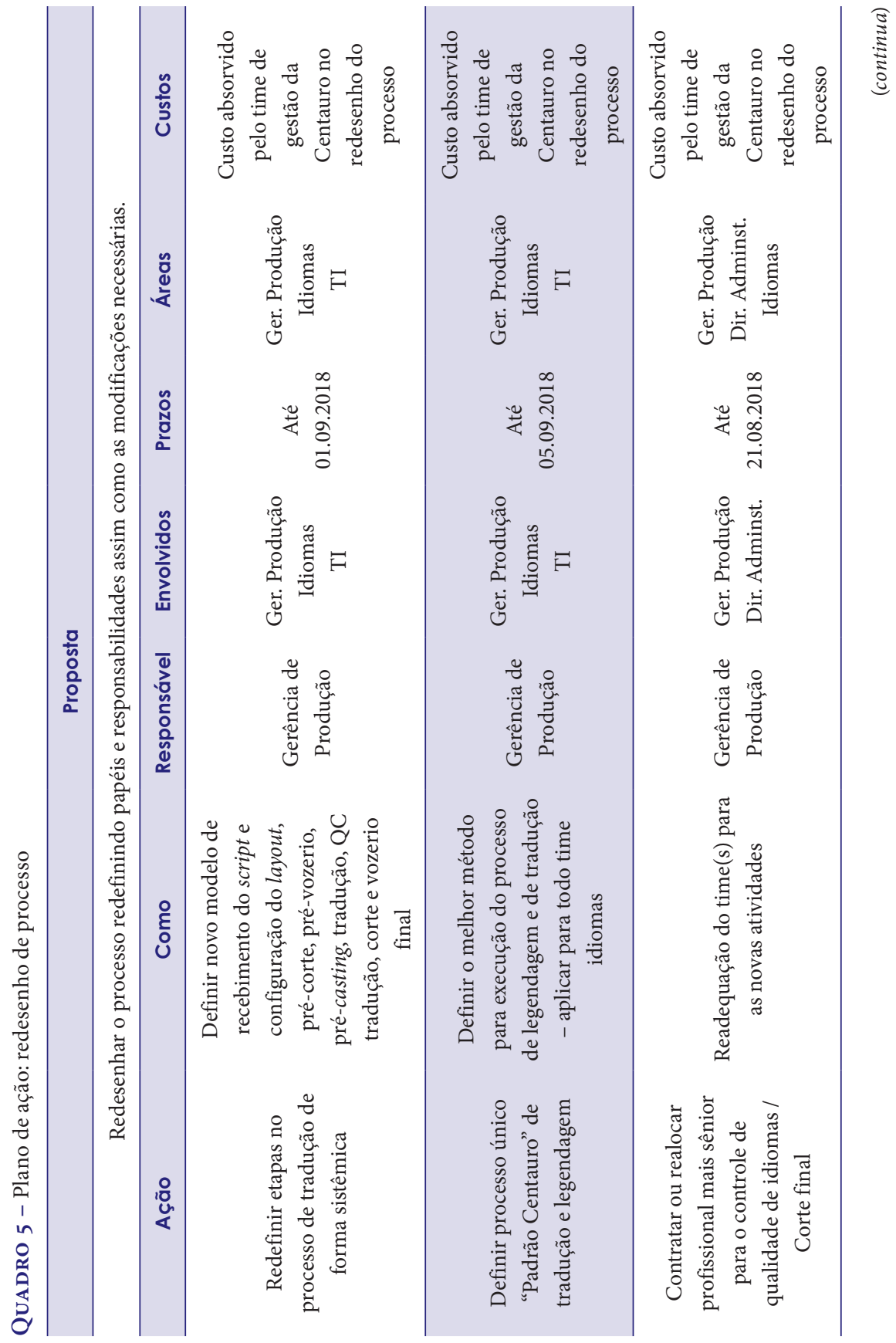




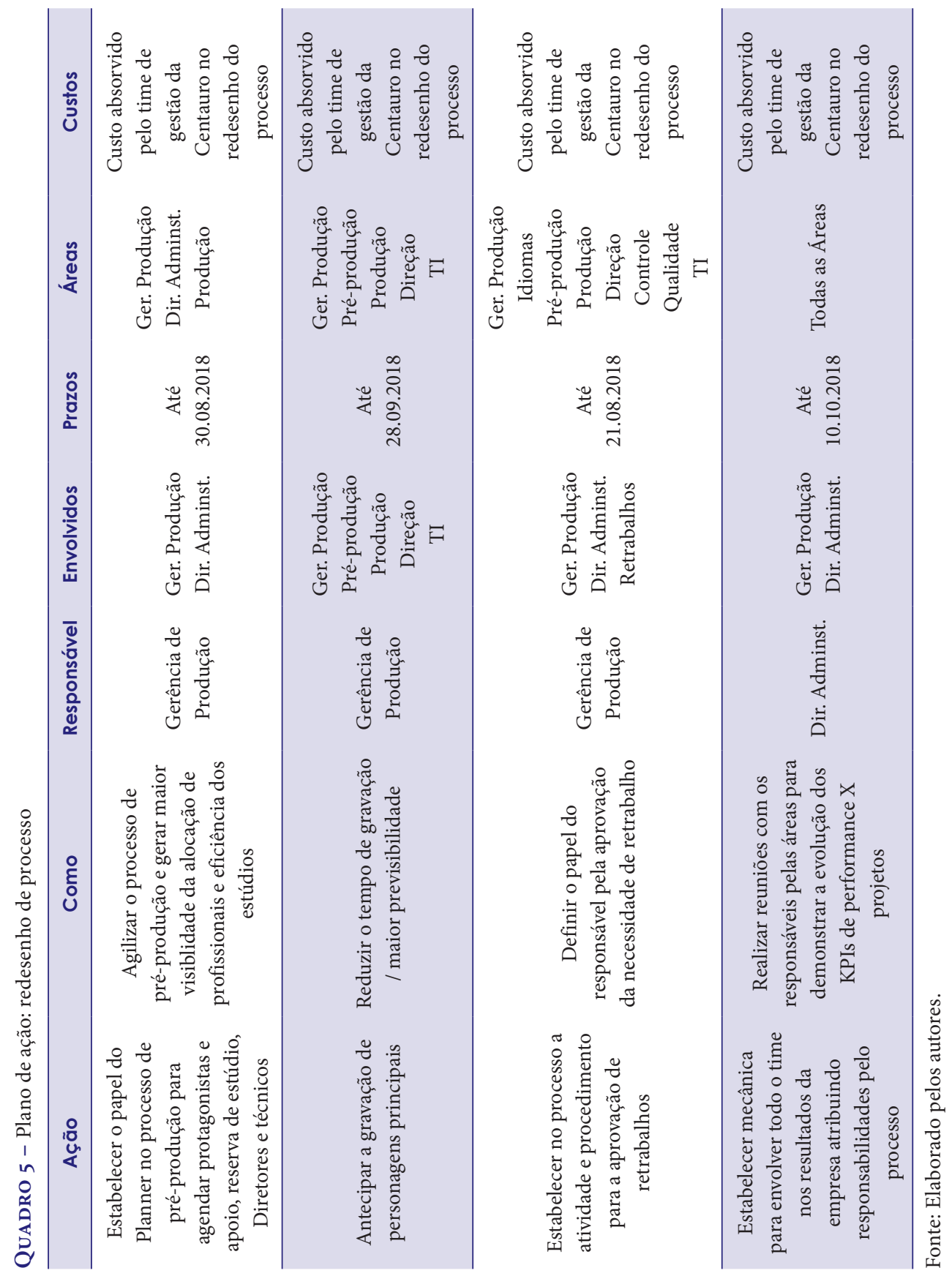


DENNIS MARQUES REIS, MARCOS ANTONIO FRANKLIN
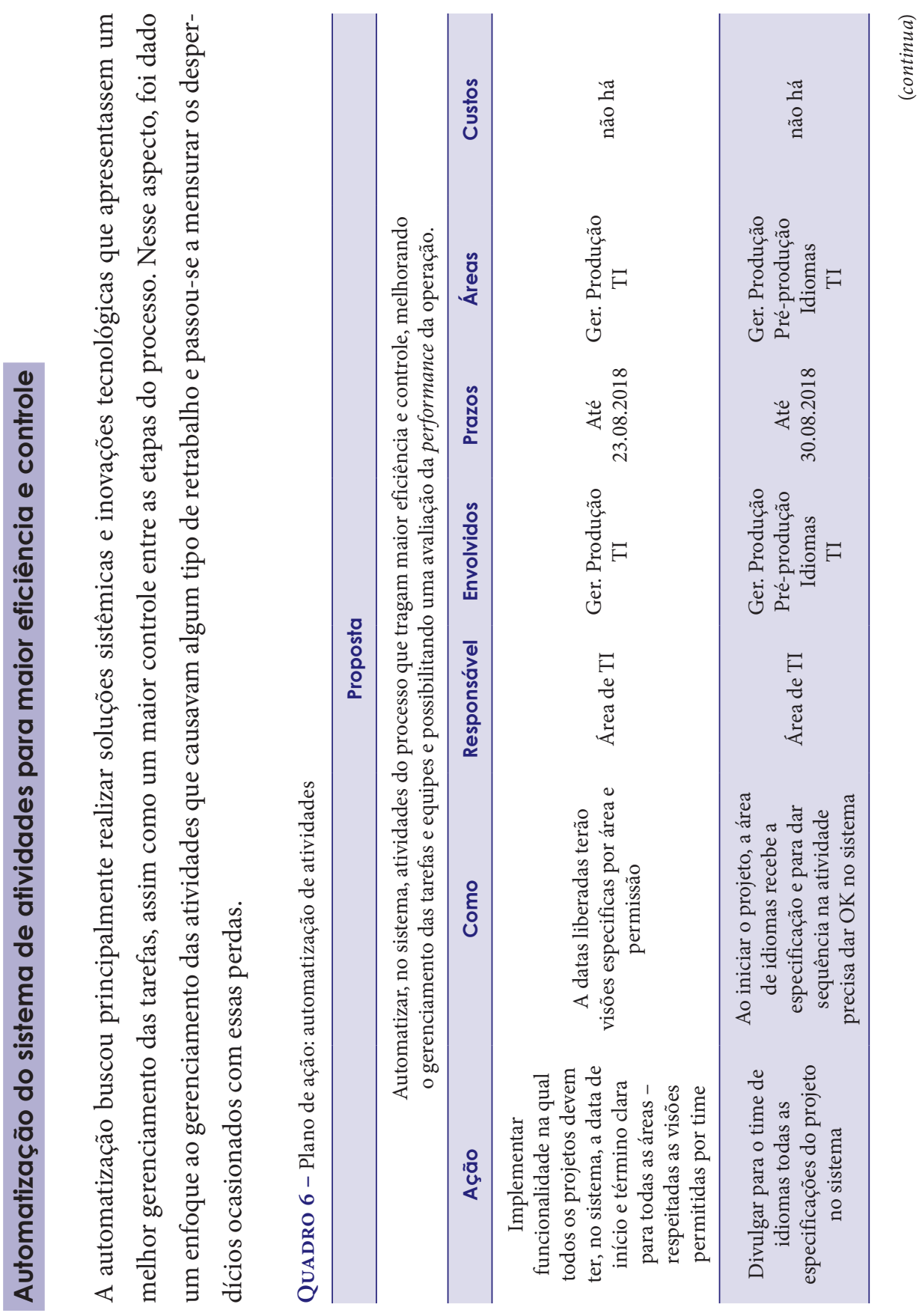


\begin{tabular}{|c|c|c|c|c|c|c|c|}
\hline$\frac{\tilde{o}}{\tilde{u}}$ & 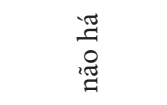 & 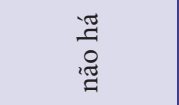 & 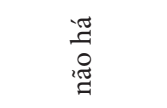 & 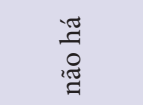 & 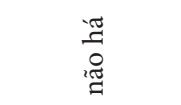 & 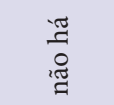 & 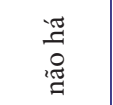 \\
\hline 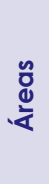 & 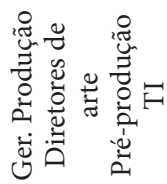 & 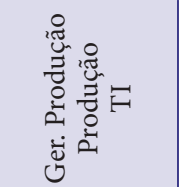 & 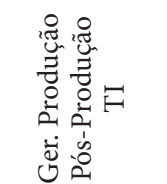 & 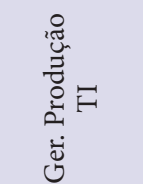 & 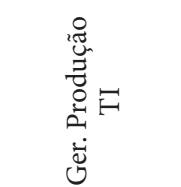 & 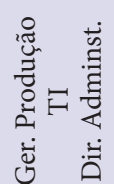 & 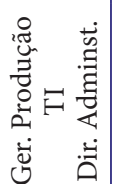 \\
\hline 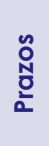 & 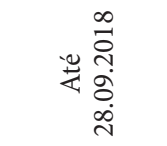 & 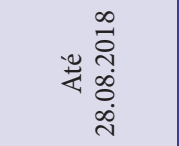 & 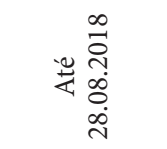 & 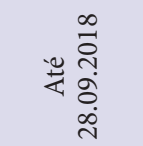 & 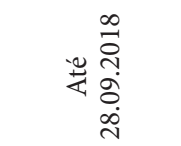 & & 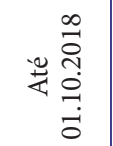 \\
\hline 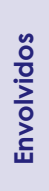 & 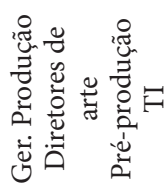 & 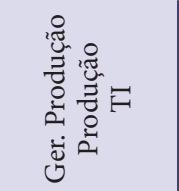 & 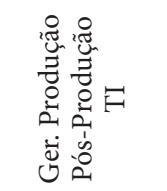 & 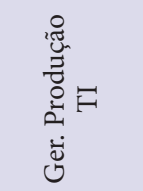 & 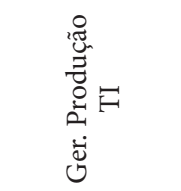 & 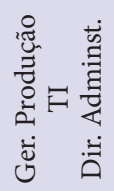 & 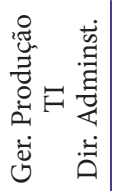 \\
\hline 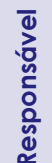 & 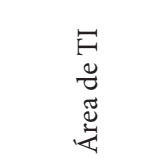 & 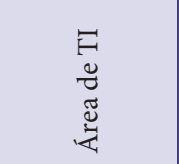 & 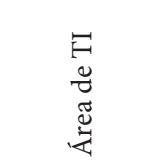 & 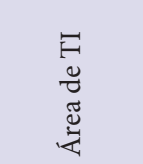 & 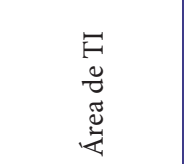 & 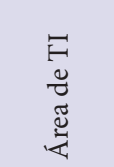 & 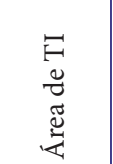 \\
\hline $\begin{array}{l}\stackrel{\circ}{0} \\
\text { o }\end{array}$ & 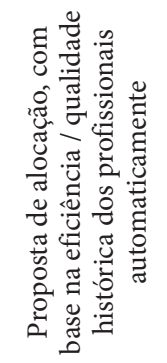 & 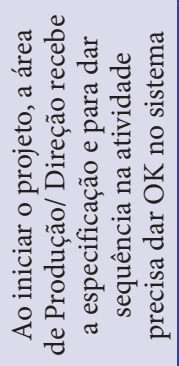 & 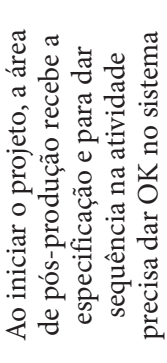 & 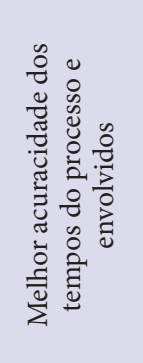 & 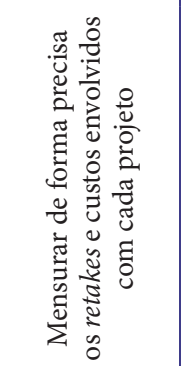 & 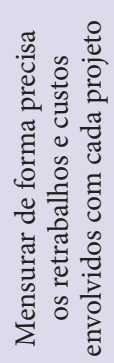 & 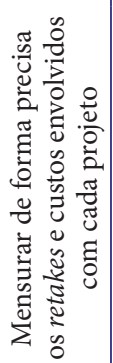 \\
\hline 葆 & 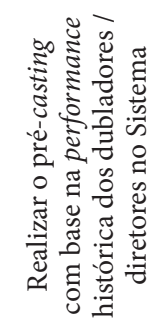 & 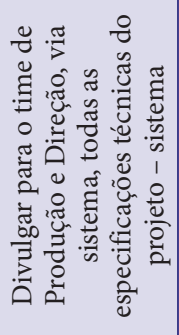 & 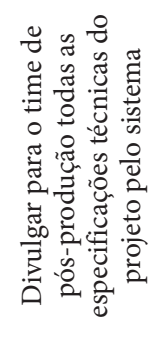 & 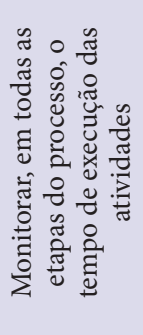 & 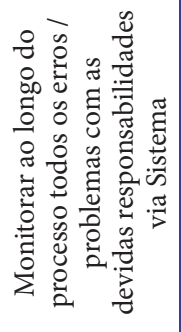 & 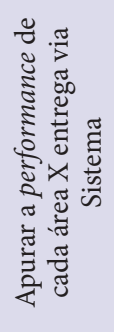 & 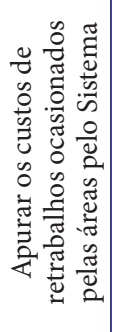 \\
\hline
\end{tabular}




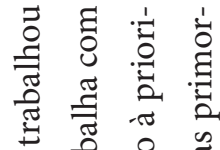

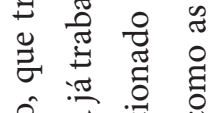

$\hat{0} \cdot \frac{\pi}{\pi} \cdot \frac{\pi}{0}$ :

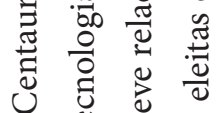

उ

:

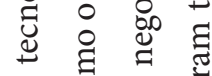

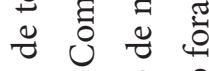

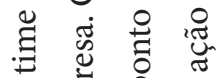

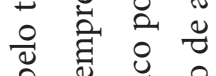

क

. 0 ह

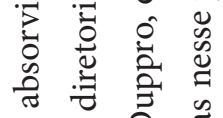

ปี艹

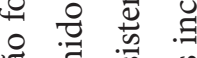

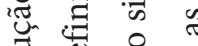

륭 잉

జ

苞节芯

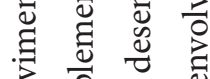

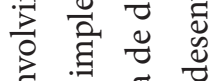

चี

范

ช

㫄

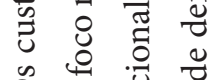

○) 0 ○

苛至

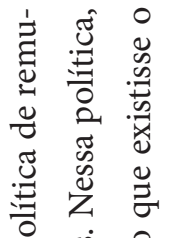

ํ.

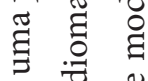

ซ $\frac{7}{0}$

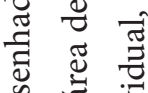

竞:

어

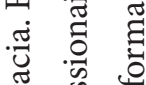

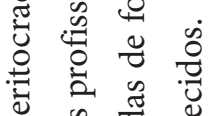

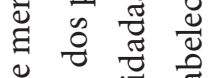

윰

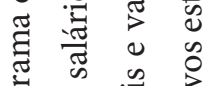

bั0 औ

ప艹

을 क

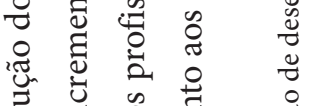

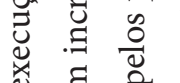

๘ ఏ ప

* $)$ 워 유

สँ

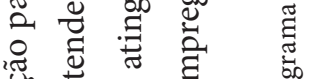

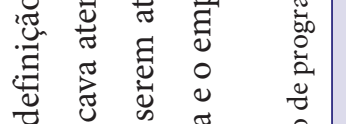

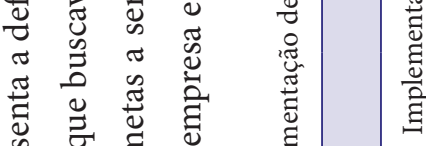

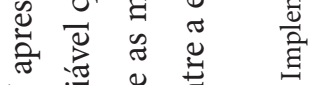

$\wedge$ 范

ํํำ

:

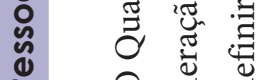
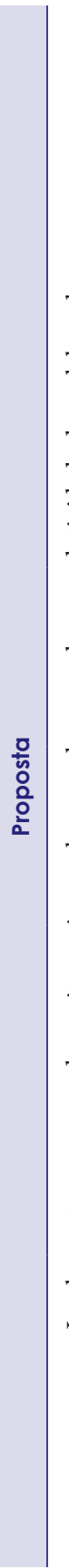

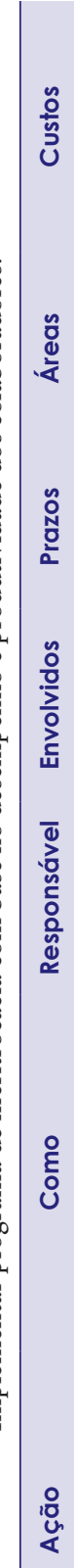

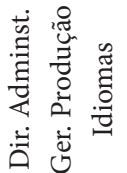

萲

胥泀

ए 4

岀

节

苑

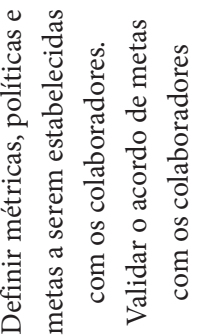

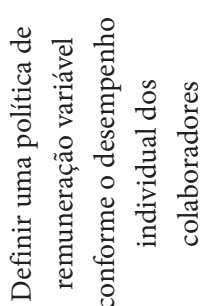


Esse processo tinha como finalidade validar a existência de um melhor desempenho dos profissionais, considerando a mudança do processo, a automatização de atividades e o incremento na remuneração mensal de cada envolvido.

\section{INTERVENÇÃO/RESULTADOS}

Os resultados foram obtidos com base na intervenção e contemplaram os três pilares propostos com solução ao problema: processos, sistemas e pessoas. A implantação de novas etapas de processos, a paralelização de atividades, o maior controle de tarefas e os novos gates contribuíram diretamente para o resultado obtido. Cabe destacar a relevância na automatização de etapas do processo no sistema Duppro, o que tornou ágil a acuracidade das informações. O redesenho do processo e sua automatização foram os grandes nortes adotados no projeto. A empresa Centauro preparou-se para atender às demandas e às solicitações de tal sorte que, basicamente, todas as melhorias propostas já foram implantadas. Na sequência, apresenta-se detalhadamente o processo redesenhado e que está sendo aplicado atualmente na empresa. Assim, o processo de produção de dublagem e legendagem passou por uma grande reformulação e teve como um dos principais direcionadores a melhoria da qualidade dos outputs gerados pelas áreas, de modo a diminuir a quantidade de erros, ao longo das etapas, e, por consequência, reduzir retrabalhos na entrega dos produtos aos clientes. As figuras 5, 6 e 7 demonstram o novo fluxo do processo, considerando as modificações realizadas na organização. 


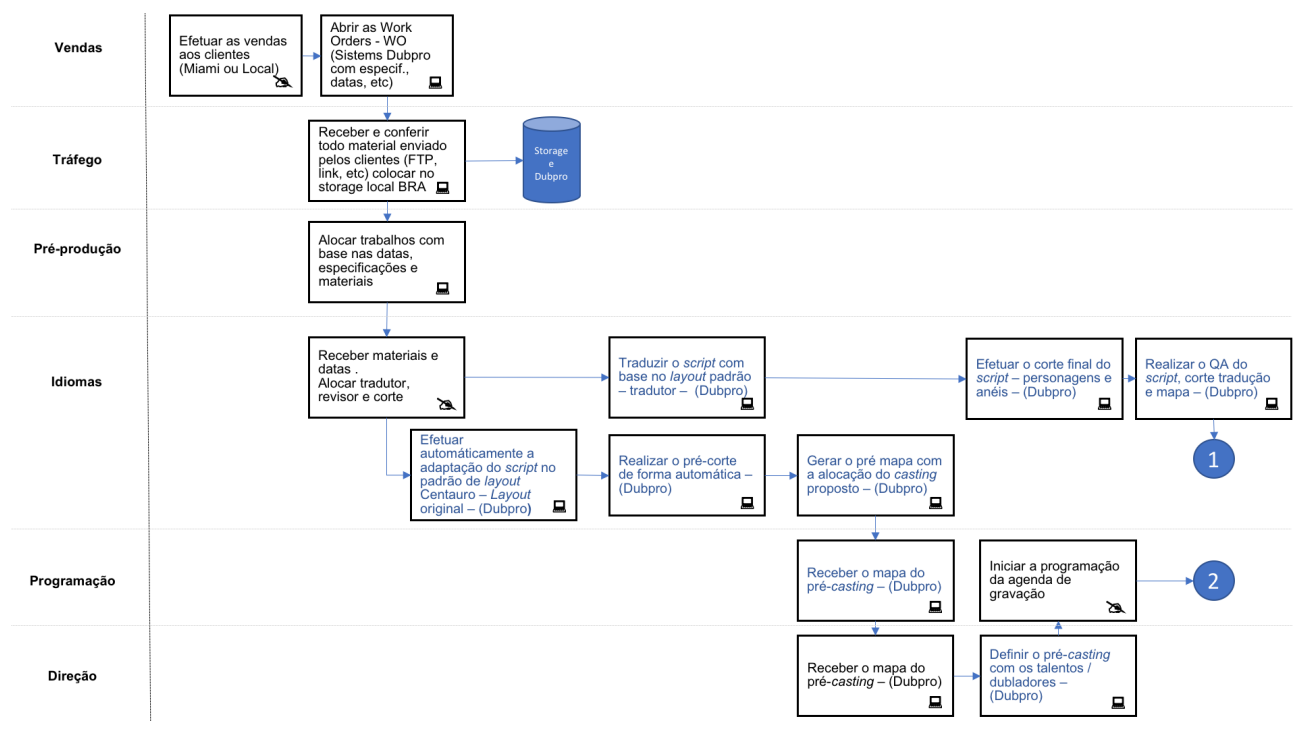

FIGURA 5 - Novo processo de produção - parte 1

Fonte: Elaborada pelos autores.

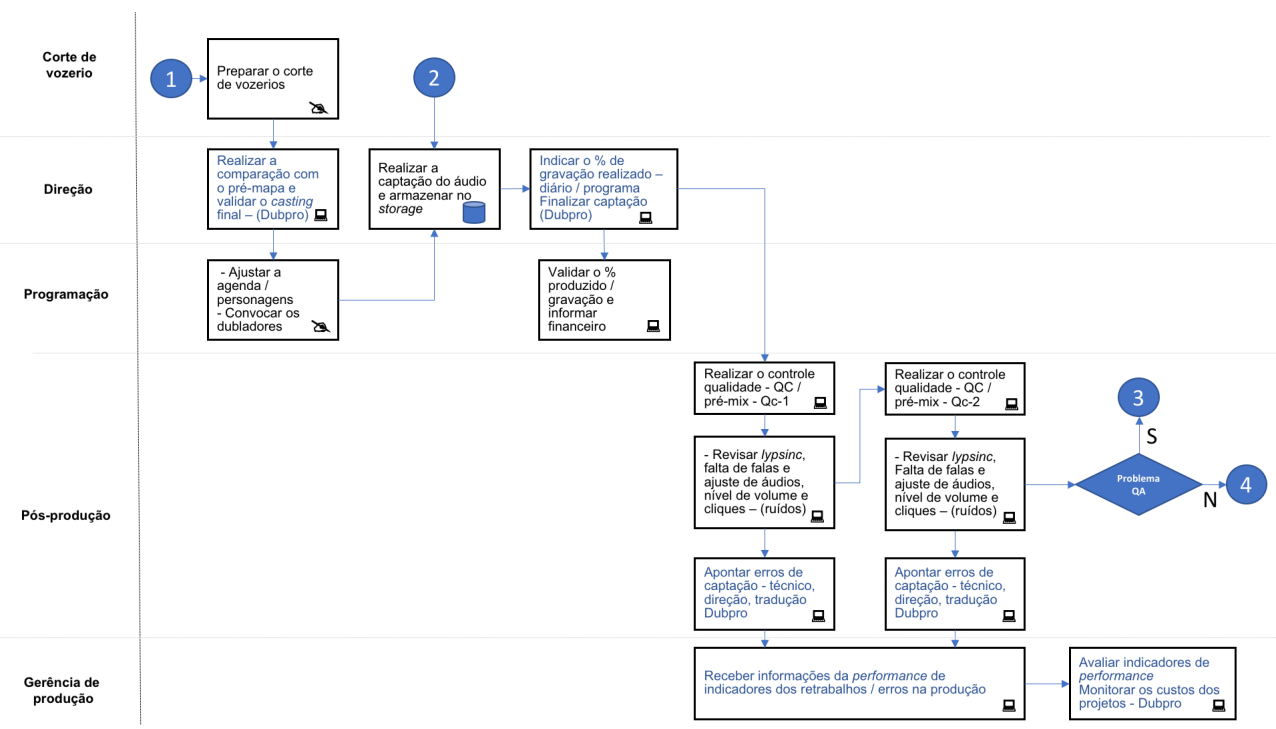

FIGURA 6 - Novo processo de produção - parte 2

Fonte: Elaborada pelos autores. 


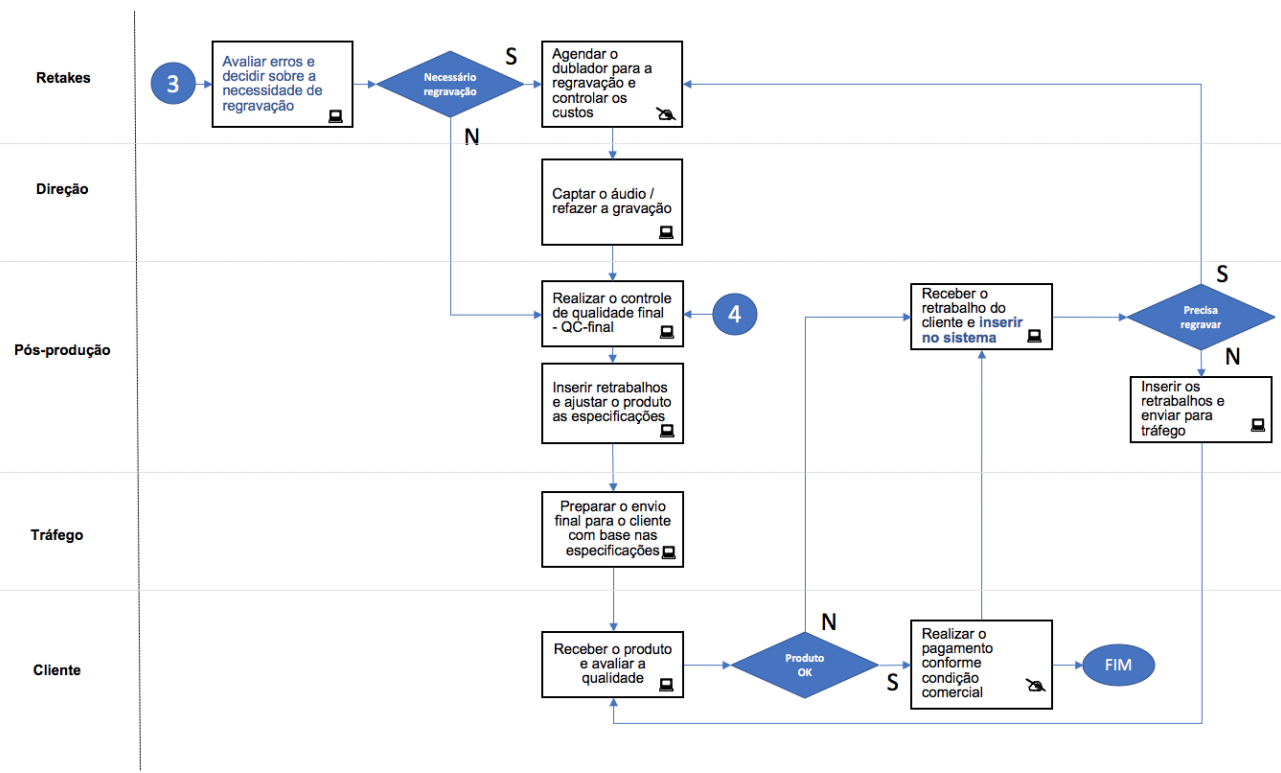

FIGURA 7 - Novo processo de produção - parte 3

Fonte: Elaborada pelos autores.

Outra realização foi a paralelização entre as atividades, permitindo, assim, que várias etapas pudessem ocorrer de forma simultânea sem que se perdessem a qualidade e a rastreabilidade das tarefas. Também foi priorizada a criação de novos gates de qualidade ao longo do processo, para que os problemas gerados pudessem ser corrigidos com maior brevidade e não prejudicassem ou onerassem a rentabilidade dos projetos. Isso pode ser observado na Figura 8, em que se demonstram as atividades realizadas e seus paralelismos. 


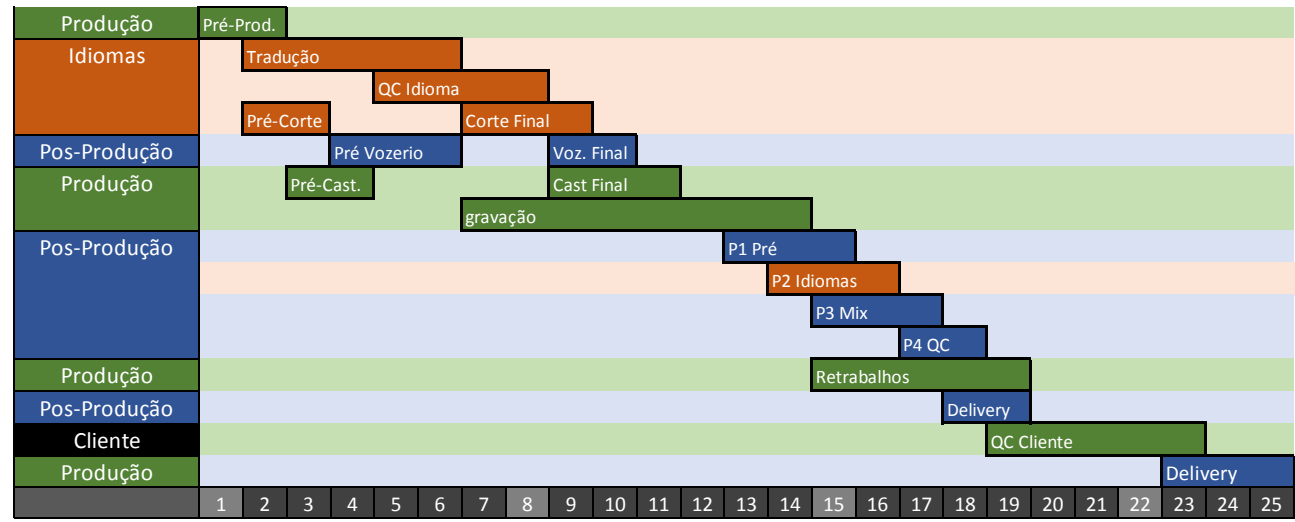

FigurA 8 - Novo tempo médio de produção

Fonte: Centauro (2018).

Também foi priorizada a criação de novos gates de qualidade ao longo do processo, para que os problemas gerados pudessem ser corrigidos com maior brevidade e não prejudicassem ou onerassem a rentabilidade dos projetos. O processo ainda se inicia com a área de vendas negociando contratos ou projetos. Na sequência, registram-se as ordens de serviço via sistema, em que são detalhadas as especificações, datas e informações adicionais do projeto. Todas essas especificações agora passam a ser disponibilizadas para as áreas de idiomas, pré-produção, programação, diretores de arte e pós-produção, via sistema, automaticamente. Dessa forma, os envolvidos no processo de produção de dublagem e de legendagem conhecem os requisitos técnicos e prazos da produção. Na sequência, iniciam-se duas frentes: 1 . a área de tráfego recebe e confere todo o material enviado pelo cliente e o disponibiliza em um storage para acesso das demais áreas; em seguida, 2. a área de pré-produção aloca os trabalhos com base nas datas e nas especificações do projeto, com os materiais disponibilizados no sistema.

A partir desse momento, a área de idiomas recebe os materiais e as datas, e providencia a alocação do tradutor que será responsável pelo trabalho. Então, de forma automática, é feita a adaptação do script original para o padrão Centauro de layout. Na sequência, o sistema já realiza o pré-corte e gera o mapa com a alocação prévia do pré-casting. 
Simultaneamente, o tradutor inicia a tradução com base nos layouts e requisitos específicos do projeto. Essa automação levou a empresa a uma inovação tecnológica e de processo, pois, a partir das mudanças, puderam-se tratar quaisquer formatos de documentação de scripts recebidos nos projetos e nos diversos templates disponibilizados pelos clientes: Excel, Word, PDF etc. Além disso, houve ganho de eficiência no processo gerado pelo paralelismo de atividades. Assim, conforme Reis (2008), foi possível verificar que o principal agente de mudança no mundo atual é, de fato, a inovação tecnológica. A inovação tecnológica pode ser definida como uma nova ideia que, após um determinado tempo de execução, passou a ser usada com sucesso. A inovação pode ser considerada como uma criação original ou uma novidade, que também possa ser aplicada a um processo de produção. Para Bessant e Tidd (2009), as empresas têm que identificar como tratar as inovações e devem compreender a que lugar pretendem chegar e como a inovação pode viabilizar esse objetivo.

Na sequência, o mapa de pré-casting é recebido pelas áreas de programação e direção de arte via sistema. Os diretores de arte definem os talentos/dubladores que irão compor o projeto mediante sistema, considerando o desempenho de cada um deles pelo histórico fornecido pela aplicação. Essa também é uma inovação tecnológica aplicada no processo. A partir da seleção de talentos/dubladores, a área de programação inicia o agendamento para a gravação em estúdio.

Paralelamente, a área de idiomas realiza o corte final do script. Nesse momento, também é efetuado o QC das atividades levadas a efeito pela equipe de idiomas, sendo esse um novo gate de controle estabelecido no processo. Esse novo QC em idiomas foi implementado para reduzir o avanço do projeto sem as devidas correções. Como próximo passo, a área de corte de "vozerio" separa, na produção, os trechos nos quais podem ser aproveitadas gravações de vozerio já existentes na Centauro. A direção de arte realiza a comparação do pré-casting e valida o mapa no sistema. Com base nessa informação, a programação ajusta a agenda de personagens e convoca os demais dubladores para a gravação. Os diretores de arte realizam a captação do áudio nos estúdios de gravação e o armazenam nos storages específicos dos projetos. 
Quando da finalização do projeto, deve ser sinalizada, portanto, a finalização da captação. Os erros apurados durante o processo de gravação também são reportados ao sistema, apontando em qual etapa esse erro ocorreu: idioma, corte ou mapa. Essa nova etapa de QC também visa impedir o avanço do projeto com erros às etapas posteriores. A programação valida no sistema, diariamente, o percentual apontado pelos diretores de arte sobre as gravações realizadas e informa a área financeira. Mesmo com a gravação dos personagens em andamento, já é possível realizar a primeira etapa do controle de qualidade (QC1) pela pós-produção. Nessa etapa, o pré-mix revisa a falta de falas, ajustes de áudio, níveis de volumes e ruídos. Na sequência, é realizado o segundo controle de qualidade (QC2). Quando a área de pós-produção identifica um erro no projeto que está sendo produzido, encaminha o problema para a área de retrabalhos, que decide sobre a necessidade ou não da regravação. Todo o processo de decisão é registrado no sistema, que monitora os custos extraordinários gerados pelo retrabalho. Tanto os projetos nos quais houve algum tipo de retrabalho quanto os que não necessitaram de ajustes após a análise do QC1 e QC2 são encaminhados para a área de pós-produção, objetivando o QC final. Nesse momento, inserem-se os ajustes finais da produção e a adequação do produto, além das especificações técnicas dos clientes. Essa atividade é registrada no sistema monitorando o processo. $\mathrm{O}$ tráfego prepara o envio para o cliente com base nas especificações.

O cliente recebe o produto e avalia a qualidade. Quando não há nenhum problema técnico percebido pelo cliente, realiza-se o pagamento, e a área de finanças encerra as pendências monetárias. Caso algum problema ainda seja identificado, a área de pós-produção recebe o retrabalho a ser incluído. Pôde-se notar que houve a criação de novas atividades e o fortalecimento de papéis dentro do processo redesenhado. Isso pôde ser percebido na criação da área de retrabalhos, que passou a ser peça fundamental na decisão da aprovação de regravação de áudios no estúdio. Outro ponto sensível foi a mudança no escopo e na atuação da área de idiomas, que passou a ter um papel protagonista no início do processo. Outras áreas também passaram a ser responsáveis pelo apontamento dos erros percebidos ao longo do processo, como a produção e os diretores de arte, que agora reportam as divergências encontradas nas etapas anteriores às suas atividades. 
Esses controles ajudam a prevenir que projetos caminhem de forma indiscriminada e os erros só sejam percebidos quando da entrega ao cliente. A gerência de produção passou a ter uma série de controles ao longo do processo, o que favorece que sejam tomadas medidas corretivas na execução de um projeto e possam ser efetuadas melhorias contínuas decorrentes da observação de desvios constantes.

Outro ponto que trouxe benefício ao processo foi a redução do tempo de entrega dos produtos aos clientes. Como citado no tópico "Entendimento do problema", o processo que era realizado anteriormente pela Centauro levava, em média, 35 dias para entregar um projeto aos seus clientes. Com o redesenho, esse tempo foi reduzido para aproximadamente 25 dias. Conforme o Gráfico 2, é possível verificar uma redução média de 8,6 dias para a entrega final dos produtos nos meses de agosto, setembro e outubro.

Quantidade de dias antecipados

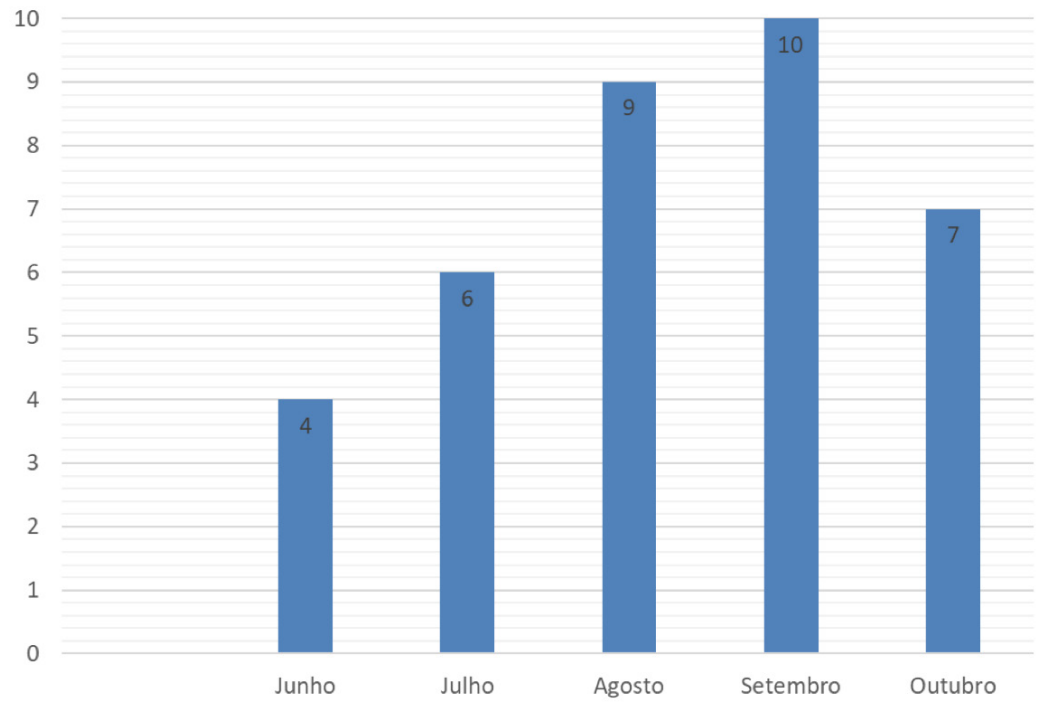

GRÁfICO 2 - Redução de dias - projetos VC Medios (2018)

Fonte: Centauro (2018).

O novo processo implementado permite que várias atividades possam ser praticadas paralelamente de forma a entregar a versão final ao cliente com menor prazo. O cliente 
ainda mantém seu prazo de avaliação e de solicitação de correções no produto, que também são efetuados, de forma abreviada, pela Centauro, garantindo, assim, a entrega dos projetos em até 25 dias. Esse paralelismo e os ajustes no processo já vêm entregando resultados na execução dos projetos. Foi mensurado o prazo de entregas dos projetos no cliente VC Medios e percebeu-se que a redução está acontecendo conforme planejado.

Outro fator introduzido e que apresentou resultado foi a antecipação de gates de qualidade, como na área de idiomas e de produção, conforme representado no Gráfico 3.

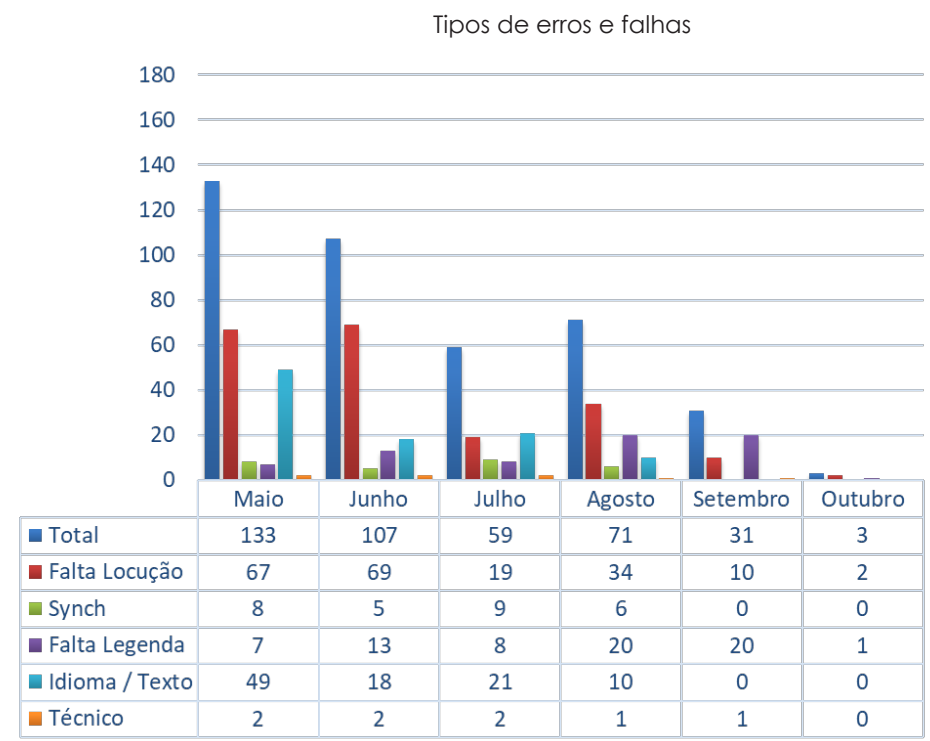

GráfICO 3 - Redução de erros - projetos VC Medios (2018)

Fonte: Centauro (2018).

Assim como a redução de erros apresentados nos projetos da VC Medios, também se pôde observar a redução de retrabalhos nos projetos executados para esse cliente. No período de agosto, os retrabalhos representavam $20 \%$ do total de projetos entregues. Esse número foi reduzido para $14 \%$ no mês de setembro e para apenas $4 \%$ em outubro. Esses dados podem ser observados, com maior profundidade, no Gráfico 4, que retrata a redução de retrabalhos na empresa. Vale notar que, no mês de maio, os retrabalhos giravam em torno de $44 \%$ nos projetos. 


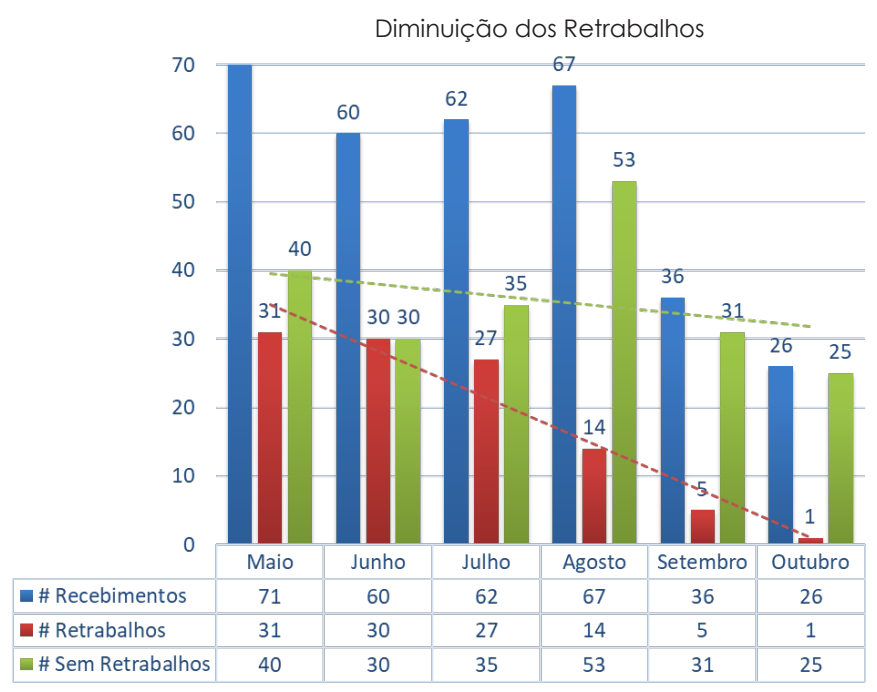

GrÁFICO 4 - Redução de retrabalhos - projetos VC Medios

Fonte: Centauro (2018).

Nota-se que houve uma redução grande na quantidade de erros apontados. Entre os meses de agosto e outubro, os erros apurados passaram de 71 para apenas três. A área de idiomas era responsável por uma grande quantidade de erros e, no mês de outubro, cometeu apenas um. Os dados apresentados também são de projetos do cliente VC Medios e retratam informações fornecidas pela área de pós-produção, apurados no QC final. No Gráfico 5, podem ser verificados os valores economizados com a redução de retrabalhos.

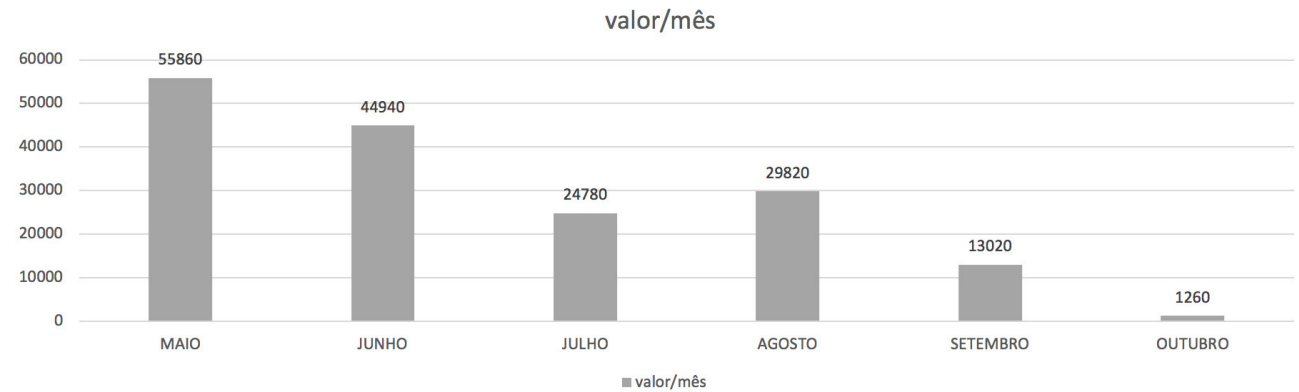

GRÁFICO 5 - Redução de custos com retrabalhos - projetos VC Medios (2018)

Fonte: Centauro (2018). 
A redução de retrabalhos, na execução de projetos, apresentou melhora no desempenho da empresa. As perdas financeiras e operacionais têm sido mais bem administradas e comprovam que as mudanças no processo surtiram efeitos positivos na organização. Quando apuradas as perdas financeiras nos produtos entregues à empresa VC Medios, observa-se uma melhora efetiva no resultado da operação. No mês de maio, a perda com retrabalho foi de $\mathrm{R} \$ 55.860,00$. Já em agosto, quando algumas melhorias e a automatização no processo haviam sido implementadas, o valor com as perdas ficou em R \$29.820,00. O último mês de apuração foi outubro e a perda apresentada foi de somente R \$1.260,00, comprovando, assim, a efetividade das inovações de processo e tecnológicas utilizadas. Esses valores salvos com a melhor eficiência da operação trouxeram uma melhor rentabilidade aos projetos e à organização.

Finalizando a análise sobre a intervenção realizada na Centauro, observa-se o desempenho da área de idiomas, que foi a escolhida para o piloto, relacionada à meritocracia. Para a realização dessa medição de desempenho, foram estabelecidos com o time os principais indicadores a serem monitorados, bem como a escala de pontuação e o percentual de incremento no salário ocasionado pelo cumprimento das metas estabelecidas. Os indicadores monitorados foram: tradução por palavra, legendas por minuto, dublagem por minuto e por erros nas dublagens e legendagens.

A medição realizada nos meses de agosto, setembro e outubro trouxe dados relevantes a serem considerados na efetividade do programa adotado. Houve distintos comportamentos entre os membros do time: alguns superaram as metas estabelecidas e, por consequência, conseguiram a remuneração adicional, e outros colaboradores permaneceram com o desempenho atual ou pioraram suas entregas ao longo dos meses. Esses pontos trazem uma reflexão sobre a efetividade do programa implementado, quanto à dificuldade de atingimento das metas, à atratividade da remuneração adicional oferecida ou mesmo quanto à complexidade na aplicação da avaliação. Os dados relacionados à medição de indicadores podem ser observados no Gráfico 6. 


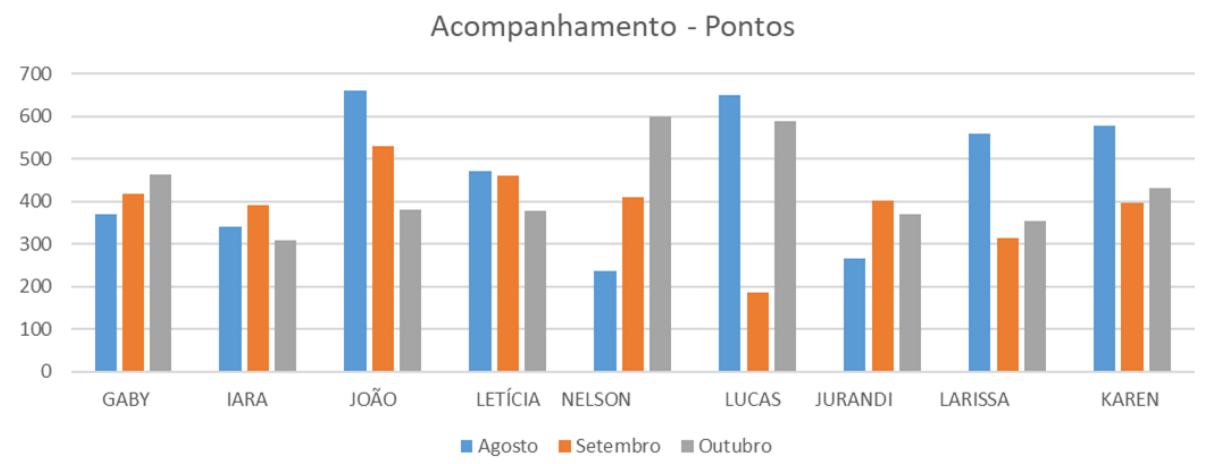

GRÁfICo 6 - Desempenho área de idiomas - 2018

Fonte: Centauro (2018).

\section{CONSIDERAÇÕES FINAIS E CONTRIBUIÇÕES}

A proposta deste trabalho foi efetivar a redução de retrabalhos no principal processo de negócio da empresa Centauro Comunicaciones Brasil. A aplicação de técnicas possibilitou que os planos de ação pudessem ser concretizados. Conforme apresentado na intervenção, resultados positivos foram alcançados nas perdas operacionais e financeiras. As pessoas envolvidas colaboraram de forma efetiva e conduziram as modificações propostas para suas rotinas de trabalho e de processos.

Todas as negociações realizadas para as mudanças necessárias foram aprovadas e ajustadas pela diretoria e por seus times. A diretoria da empresa ajustou as arestas que haviam de divergência no processo e, de forma coesa, vem implementando as melhorias não somente na operação brasileira, mas também replicando na unidade da Colômbia.

O responsável pelas operações e contas, Javier Gagliano, recebeu uma cópia do trabalho final e afirmou que este promoveu inúmeras melhorias nos processos internos da Centauro. Acesse o link da Universidade Presbiteriana Mackenzie e veja a cobertura da entrega.

A Centauro, em sua página oficial no LinkedIn, apresenta um depoimento do gerente de operações sobre os resultados das melhorias nos processos organizacionais 
pelo projeto realizado. O conteúdo pode ser observado no link: https://www.linkedin. com/posts/javiergagliano_no-dia-5-de-junho-recebemos-dennis-marques-activity-6545343902256254976-6Tkv.

Houve a possibilidade de implantar as inovações tecnológicas propostas no processo, pois ocorreram o comprometimento e a rapidez no desenvolvimento das melhorias necessárias no sistema Duppro. A aplicação da gestão de projetos ágeis, no desenvolvimento das melhorias, permitiu que pudessem ser corrigidas ou modificadas eventuais decisões em pleno progresso das atividades, viabilizando, dessa forma, que erros pudessem ser corrigidos de forma abreviada. A maior complexidade enfrentada, no entanto, esteve relacionada à política de meritocracia implementada ao desempenho da área de idiomas.

Cabe ressaltar que o desenvolvimento deste trabalho foi possível devido ao engajamento da alta gestão da empresa Centauro. A experiência adquirida, por meio de mais de 300 horas neste trabalho, poderá ser compartilhada com outras empresas independentemente do segmento de atuação, sobretudo aquelas que enfrentem problemas similares aos de retrabalhos, de perdas operacionais e financeiras em seus processos de negócio.

\section{INNOVATION IN THE DUBBING AND SUBTITLING PRODUCTION PROCESS TO REDUCE OPERATIONAL AND FINANCIAL LOSSES AND REWORK}

\section{ABSTRACT}

Using the approach of Marcondes et al. (2017), this technological report had the purpose of presenting solutions to the problem of efficiency in the production process of the company Centauro Comunicaciones, from the dubbing and subtitling sector. The company is headquartered in Bogotá - Colômbia, and the Brazilian operation in São Paulo - Capital. In order to understand the problem, a diagnosis was made using the techniques of interview, brainstorm, Swot and qualitative research. The purpose of this work was to seek to reduce rework and operational and financial losses in the dubbing and subtitling production process. After the diagnosis was made, problems in processes, technology and people were identified. Thus, proposals for solutions were prepared with their respective action plans: the application of technological innovation, considering the process redesign, the automation of activities and the 
performance evaluation program of professionals. The complexity in preparing the work was high, as it required the company to adopt the meritocracy policy, taking employees to a new culture of remuneration, based on the result with differentiated productivity, linked to greater gain. As a result, the impacts obtained were: 1. Deadline reduction for delivering customer projects, from an average of 35 days to 25; 2. Drop in the rework rate, that is, in May 2018, around 44\%; August, 20\%; September, 14\%; reaching 4\% in October; and 3. Financial results: the loss on rework was R\$55.860,00 in May 2018, in August of same year it was reduced to $\mathrm{R} \$ 29,820.00$ and, in October, to $\mathrm{R} \$ 1,260.00$.

\section{KEYWORDS}

Reworks. Technological innovation. Process. Performance evaluation.

\section{REFERÊNCIAS}

ANDREOLI, T. P.; ROSSINI, F. Organização, sistemas e métodos. Curitiba: InterSaberes, 2015. ASSOCIATION OF BUSINESS PROCESS MANAGEMENT PROFESSIONALS. BPM CBOCK: guia para o gerenciamento de processos de negócio: corpo comum de conhecimento. Brasília: ABPMP Brasil, 2013.

BARBOSA, I.; LÍRIO, J. (2015). Versão brasileira: a dublagem toma conta do Brasil. 2015. Disponível em: https://jornalismoespecializadounesp.wordpress.com/2015/09/29/versao-brasileira-a-dublagem-toma-conta-do-brasil. Acesso em: 15 maio 2018.

BESSANT, J.; TIDD, J. Inovação e empreendedorismo. Porto Alegre: Bookman, 2009.

CAETANO, C. I.; SAMPAIO, P. P. P. Planejamento estratégico e administração em segurança. Curitiba: InterSaberes, 2016.

COELHO, B. C. et al. (2017). Os efeitos causados pelo retrabalho nas etapas do processo produtivo de uma indústria fabricante de ferritas magnéticas. In: SIMPÓSIO DE ENGENHARIA DE PRODUÇÃO, 5, 2017. Anais [...]. Disponível em: https://even3.azureedge.net/ anais/43133.pdf. Acesso em: 11 ago. 2020.

FLICK, U. Introdução à pesquisa qualitativa. Porto Alegre: Bookman, Artmed, 2009.

KOTLER, P.; ARMSTRONG, G. Princípios de marketing. 12. ed. São Paulo: Pearson Prentice Hall, 2007. 
LAFETÁ, F. G.; BARROS, C. F. O.; LEAL, P. O. C. D. Projetos complexos: estudo de caso sobre a complexidade dos projetos de engenharia de telecomunicações em uma empresa do setor de óleo e gás. Revista de Gestão e Projetos, v. 7, n. 1, p. 41-55, 2016.

LUCENA, M. D. S. Planejamento estratégico e gestão do desempenho para resultados. São Paulo: Atlas, 2004.

MARIA, L. A dublagem brasileira mostra toda sua força e tem profissionais em BH. O Tempo, 2017.Disponívelem:https://www.otempo.com.br/divers\%C3\%A3o/magazine/a-dublagembrasileira-mostra-toda-sua-for\%C3\%A7a-e-tem-profissionais-em-bh-1.1518301. Acesso em: $1^{\circ}$ maio 2018.

MARCONDES, R. C.; MIGUEL, L. A. P.; FRANKLIN, M. A.; PEREZ, G. Metodologia para trabalhos práticos e aplicados: administração e contabilidade. São Paulo: Editora Mackenzie, 2017.

OLIVEIRA, D. P. R. Sistemas, organização e métodos. São Paulo: Atlas, 1997.

OLIVEIRA, V. M. A. D.; MARTINS, M. D. F.; VASCONCELOS, A. C. F. Entrevistas "em profundidade" na pesquisa qualitativa em administração: pistas teóricas e metodológicas. SIMPOI - Simpósio de Administração da Produção e Operações Internacionais. Fundação Getúlio Vargas. São Paulo. p. 1-12, 2012.

REIS, D. R. dos. Gestão da inovação tecnológica. Barueri: Manole, 2008.

SUTHERLAND, J. A arte de fazer o dobro do trabalho na metade do tempo. São Paulo: LeYa, 2014.

TOlEDO, J. C. de; BORRÁS, A.; MERGUlHÃO, M. A.; MENDES, R. C.; HENRIQUE, G. Qualidade: gestão e métodos. Rio de Janeiro: LTC. 2012.

UNIVERSIDADE PRESBITERIANA MACKENZIE. Centro de Ciências Sociais e Aplicadas. Mestrado Profissional em Administração do Desenvolvimento de Negócios. Disponível em: https://www.mackenzie.br/pos-graduacao/mestrado-doutorado/sao-paulo-higienopolis/administracao-do-desenvolvimento-de-negocios-profissional/noticias-e-eventos/ arquivo/n/a/i/aluno-do-mpadn-apresenta-seu-trabalho-de-conclusao-a-empresa-centauro-comunicaciones-de-dublagem-e-1/. Acesso em: 5 ago. 2020.

VIDAL, A. Agile Think ${ }^{\circledast}$ Canvas. São Paulo: Brasport, 2017. 